\title{
Headache Attributed to Vaccination Against COVID- 19 (Coronavirus SARS-CoV-2) with the ChAdOx1 nCoV-19 (AZD1222) Vaccine: A Multicenter Observational Cohort Study
}

\author{
Carl H. Göbel (D) · Axel Heinze · Sarah Karstedt · Mascha Morscheck • \\ Lilian Tashiro • Anna Cirkel • Qutyaba Hamid · Rabih Halwani • \\ Mohamad-Hani Temsah · Malte Ziemann · Siegfried Görg • \\ Thomas Münte $\cdot$ Hartmut Göbel (D)
}

Received: June 14, 2021 / Accepted: July 15, 2021 / Published online: July 27, 2021

(c) The Author(s) 2021

\section{ABSTRACT}

Introduction: The most frequently reported neurological adverse event of ChAdOx1 nCoV19 (AZD1222) vaccine is headache in 57.5\%. Several cases of cerebral venous thrombosis (CVT) have developed after vaccination. Headache is the leading symptom of CVT. For the

C. H. Göbel $(\bowtie)$ · A. Cirkel · T. Münte

Department of Neurology, University Hospital Schleswig-Holstein, Campus Lübeck, Ratzeburger Allee 160, 23538 Lübeck, Germany

e-mail: carl.goebel@neuro.uni-luebeck.de

C. H. Göbel · A. Heinze · S. Karstedt · M. Morscheck

· L. Tashiro · A. Cirkel · H. Göbel

Kiel Migraine and Headache Centre, Kiel, Germany

Q. Hamid · R. Halwani

Sharjah Institute of Medical Research, University of Sharjah, Sharjah, United Arab Emirates

\section{Q. Hamid · R. Halwani}

Department of Clinical Sciences, College of Medicine, University of Sharjah, Sharjah, United Arab Emirates

M.-H. Temsah

College of Medicine, King Saud University, Riyadh, Kingdom of Saudi Arabia

\section{Ziemann · S. Görg}

Institute of Transfusion Medicine, University

Hospital Schleswig-Holstein, Campus, Lübeck, Germany differential diagnosis of headaches attributed to this vaccine and headaches attributed to CVT, it is of central clinical importance whether and, if so, how the phenotypes and course of these headaches can be differentiated. The study aims to examine in detail the phenotype of headache attributed to this vaccine.

Methods: Data on the clinical features and corresponding variables were recorded using a standardized online questionnaire in this multicenter observational cohort study. The primary outcomes of this study are the clinical features of headaches after vaccination.

Findings: A total of 2464 participants reported headaches after vaccination with the ChAdOx1 nCoV-19 (AZD1222) vaccine. On average, headaches occurred $14.5 \pm 21.6 \mathrm{~h}$ after vaccination and lasted $16.3 \pm 30.4 \mathrm{~h}$. A bilateral location was described by $75.8 \%$ of participants. This is most often found on the forehead (40.0\%) and temples (31.4\%); 50.4\% reported a pressing and $37.7 \%$ a dull pain character. Headache intensity was most often severe $(38.7 \%)$, moderate $(35.2 \%)$, or very severe (15.5\%). Accompanying symptoms were most commonly fatigue $(44.8 \%)$, chills $(36.1 \%)$, exhaustion (34.9\%), and fever (30.4\%).

Conclusion: Headaches attributed to COVID19 vaccination with the ChAdOx1 nCoV-19 (AZD1222) vaccine demonstrate an extensive and characteristic complex of symptoms. The 
findings have several important clinical implications for the differentiation of post-vaccinal headache and other primary as well as secondary headaches.

Keywords: COVID-19; Novel coronavirus SARS-CoV-2; ChAdOx1 nCoV-19 (AZD1222) vaccine; Vaccination; Side effects; Cerebral venous thrombosis; Headache; International Classification of Headache Disorders; ICHD-3

\section{Key Summary Points}

\section{Why carry out this study?}

The most frequently reported neurological adverse event of ChAdOx1 nCoV-19 (AZD1222) vaccine is headache in $57.5 \%$.

Several cases of cerebral venous thrombosis (CVT) have developed after vaccination. Headache is the leading symptom of CVT.

For the differential diagnosis of headaches attributed to this vaccine and other primary or secondary headaches, it is of central clinical importance whether and, if so, how the phenotypes and course of these headaches can be differentiated.

The study aims to analyze and describe in detail the phenotype of headache attributed to ChAdOx1 $\mathrm{nCoV}-19$ (AZD1222) vaccine.

\section{What was learned from the study?}

Headaches attributed to COVID-19 vaccination with the ChAdOx1 nCoV-19 (AZD1222) vaccine demonstrate an extensive complex of symptoms.

The specific set of accompanying symptoms, along with the temporal and spatial headache characteristics describe a characteristic headache phenotype for headaches attributed to COVID-19 vaccination.
The findings have several important clinical implications for the differentiation of post-vaccinal headache and headache due to cerebral venous thrombosis as a complication of vaccination.

On the basis of this analysis and by analogy to the ICHD-3, we are proposing new diagnostic criteria of headaches attributed to COVID-19 vaccination with the ChAdOx1 nCoV-19 (AZD1222) vaccine.

\section{INTRODUCTION}

In December 2019, cases of atypical viral pneumonia of unknown cause became known in Wuhan, China. A novel coronavirus, severe acute respiratory syndrome coronavirus 2 (SARS-CoV-2), was identified as the causative agent of this coronavirus disease (COVID-19). The virus has been spreading pandemically since then $[1,2]$. The most common symptoms are fever, cough, fatigue, breathing difficulties, and loss of smell and taste. While the infection may present with mild to moderate intensity in some patients, severe forms may result in pronounced dyspnea, respiratory failure, and ultimately death [3]. In addition to behavioral interventions, such as social distancing, newly developed vaccinees that are available since the second half of 2020 are the most important countermeasures to prevent the spread of the virus [4].

According to the available data, vaccinees approved by regulatory authorities so far have a positive efficacy and side effect profile [4-11]. Worldwide, there are currently 66 vaccinees in clinical and 176 in preclinical development [4], some of which are already approved. This study is part of a series of analyses of headache as a side effect following vaccination against COVID-19 with various vaccinees. Here we report on the phenotype of headache attributed to vaccination against COVID-19 (coronavirus 
SARS-CoV-2) with the ChAdOx1 nCoV-19 (AZD1222) vaccine.

ChAdOx1 nCoV-19 (AZD1222) vaccine is a monovalent vaccine composed of a single recombinant, replication-deficient chimpanzee adenovirus (ChAdOx1) vector encoding the S glycoprotein of SARS-CoV-2 [9, 12-21]. The vaccine is administered intramuscularly in two doses given between 4 and 12 weeks apart. It is indicated for active immunization to prevent COVID-19 caused by SARS-CoV-2 in individuals 18 years of age and older $[9,14]$. According to the data available, the most frequently reported neurological adverse event attributed to vaccination against COVID-19 (coronavirus SARSCoV-2) with the ChAdOx1 nCoV-19 (AZD1222) vaccine is headache in $57.5 \%$ of those vaccinated $[9,14,16,22]$. Detailed information about the clinical characteristics of this headache has not yet been described. The phase 3 clinical trial results only mention that mild headaches occur in $37.6 \%$, moderate headaches in $17.6 \%$, and severe headaches in $2.4 \%$ [14].

Several cases of cerebral venous thrombosis and other unusual thrombotic events with thrombocytopenia have developed after vaccination with ChAdOx1 nCoV-19 (AZD1222) vaccine [23]. This has led to extensive age restrictions in many countries around the world, including the complete cessation of the use of this vaccine. Headache is the leading symptom of cerebral venous thrombosis [24]. For the differential diagnosis of headaches attributed to this vaccine and headaches attributed to cerebral venous thrombosis, it is of central clinical importance whether and, if so, how the phenotypes and course of these headaches can be differentiated.

Vaccination-associated headaches are not yet classified by the International Classification of Headache Disorders ICHD-3, nor are diagnostic criteria provided [25]. Furthermore, the ChAdOx1 nCoV-19 (AZD1222) vaccine is a novel vaccine not previously used [14]. A detailed clinical phenotype of vaccination-associated headaches is not known to date, including for example the precise latency between vaccination and occurrence of the headache, its duration, pain character and localization, accompanying symptoms, pain-modulating factors as well as possible comorbid conditions.

The currently undergoing global vaccination campaign against COVID-19 allows this new form of headache to be studied alongside. The aim of this study is thus to delineate the detailed clinical characteristics of headaches occurring after vaccination against COVID-19 with the ChAdOx1 nCoV-19 (AZD1222) vaccine.

\section{METHODS}

\section{Study Design and Setting}

This continuous multicenter observational cohort study accompanying the COVID-19 vaccination campaign aims to analyze the headache phenotype after vaccination with the ChAdOx1 nCoV-19 (AZD1222) vaccine. The ethics committee of the University of Kiel approved the study (D403/21), which was performed in accordance with the principles of the Declaration of Helsinki of 1964 and its subsequent revisions. All subjects gave their informed consent prior to participation.

Specific aspects of the headache phenotype and related variables are collected using a publicly available online questionnaire. The questionnaire is available in multiple languages, and it consists of 43 questions about the clinical characteristics of headaches after the COVID-19 vaccination. The questions are divided into the following groups: type of vaccine used, the occurrence of headaches after vaccination, possible headaches after previous vaccinations against other diseases, temporal parameters of the headache, headache localization, headache characteristics, headache intensity, accompanying symptoms, previous history of headaches, other comorbid diseases, and sociodemographic variables.

Here we present data collected from the vaccinees between January 8, 2021 and April 4, 2021. According to the German ordinance on the entitlement to vaccination against the SARS-CoV-2 coronavirus, vaccinations were given with the highest priority to people over the age of 80 , as well as to inhabitants and 
employees at residential care homes for the elderly. Healthcare workers at a very high risk of exposure to the SARS-CoV-2 coronavirus also received the highest priority for vaccination. Since direct contact with the vaccines is not possible because of data protection regulations, the management of the residential care homes was contacted by email and asked to pass on the information about the study to the residents and staff. Twelve thousand residential care homes in Germany were contacted. In addition, the departments responsible for organizing COVID-19 vaccinations at the university hospitals in Germany and the United Arab Emirates were contacted, asking to inform the employees about the study. Attention was also drawn to the study via the institutes' websites and social media platforms. This evaluation reports the clinical headache characteristics of those patients who received ChAdOx1 nCoV-19 (AZD1222) vaccine.

\section{Data Collection}

The data on the clinical features and corresponding variables were recorded using a standardized online questionnaire, the answers of which were collected in an online database system (questionnaire link: https:// schmerzklinik.de/impfung). Subjects were informed at the beginning of the questionnaire that data were collected anonymously, meaning that as a result of this anonymization it would not be possible to revoke participation in the study after any answers have been sent. Participants could complete the questionnaire at any time after the onset of headache, there was no time limit. Since data collection was initiated immediately with the start of the vaccination campaign, the answers generally refer to the first dose.

\section{Outcomes}

The primary outcomes of this study are the clinical features of headache after vaccination against COVID-19 with the ChAdOx1 nCoV-19 (AZD1222) vaccine. In addition, comorbidities, treatment with medication, and sociodemographic variables are analyzed.

\section{Bias and Missing Data}

Medical staff in tertiary university hospitals and people being cared for in residential care homes for the elderly are overrepresented in this study compared to the general population, as both belonged to the groups with the highest vaccination priority in Germany. The study cannot analyze headache characteristics from people who did not voluntarily participate in this study. Complete data were not available for all variables, so the denominators differ between individual analyses. Missing data were not assumed for this descriptive analysis.

\section{Statistical Analysis}

The arithmetic mean and standard deviations are used to represent continuous variables. Frequency (\%), unless otherwise stated, is used to represent categorical variables. Statistical analysis for significant differences or continuous variables was done using the $t$ test. The statistical information is based on non-missing data. The 5\% significance level $($ alpha $=0.05)$ was

Table 1 Demographic data of patients

\begin{tabular}{ll}
\hline Parameter & Value \\
\hline$n$ & 2464 \\
Sex, no. (\%) & \\
Female & $1534(84.7 \%)$ \\
Male & $276(15.2 \%)$ \\
Age at vaccination (years) & \\
Arithmetic mean & 39.0 \\
Standard deviation & 12.7 \\
Median & 39 \\
Range & $18-78$ \\
Height (cm) & $170.2 \pm 8.1$ \\
Body weight $(\mathrm{kg})$ & $75.8 \pm 18.6$ \\
\hline
\end{tabular}


considered to be statistically significant. Statistical analyzes were carried out using SPSS 27.

\section{RESULTS}

\section{Participants}

During the study period from January 8, 2021 till April 4, 2021, 2464 participants reported that headaches had occurred after vaccination against COVID-19 with the ChAdOx1 nCoV-19 (AZD1222) vaccine (Table 1). The participants consisted of $84.7 \%$ women and $15.2 \%$ men. The mean height was $170.2 \pm 8.1 \mathrm{~cm}$ and the mean body weight $75.8 \pm 18.6 \mathrm{~kg}$. The mean age was $39.8 \pm 12.7$ years at the time of vaccination, the median was 39 years, and the range was 18-78 years (Fig. 1); $92.6 \%$ of the participants reported that they had not experienced any headaches following previous vaccinations (Fig. 2) and $7.4 \%$ of the participants indicated that they had. In the latter group, $90.2 \%$ reported that the headache after COVID-19 vaccination was different from previous headaches after previous vaccinations, so only $9.8 \%$ of the participants experienced similar headaches after their COVID-19 vaccination compared to previous vaccinations. No prior history of headache disorders was reported by $35.3 \%$ of the participants; $26.9 \%$ of participants reported a tension-type headache, $15.3 \%$ a migraine, and $12.6 \%$ the coexistence of both tension-type headache and migraine; 0.9\% reported cluster headaches; $8.7 \%$ reported a history of other headache disorders (Fig. 3). The most common other comorbid diseases were metabolic/hormonal (22.7\%), pulmonary (20.8\%), and mental disorders (13.0\%). A complete list of frequencies can be found in Fig. 4 .

\section{Temporal Parameters of Headache after Vaccination Against COVID-19}

The average latency between vaccination against COVID-19 and the onset of headaches was $14.5 \pm 21.6 \mathrm{~h}$. Over half of the vaccinees experienced the headache after less than $10 \mathrm{~h}$ and $80 \%$ within $20 \mathrm{~h}$ after the vaccination. In less than $6.3 \%$ of the participants, the headaches only began more than 2 days after the vaccination (Fig. 5).

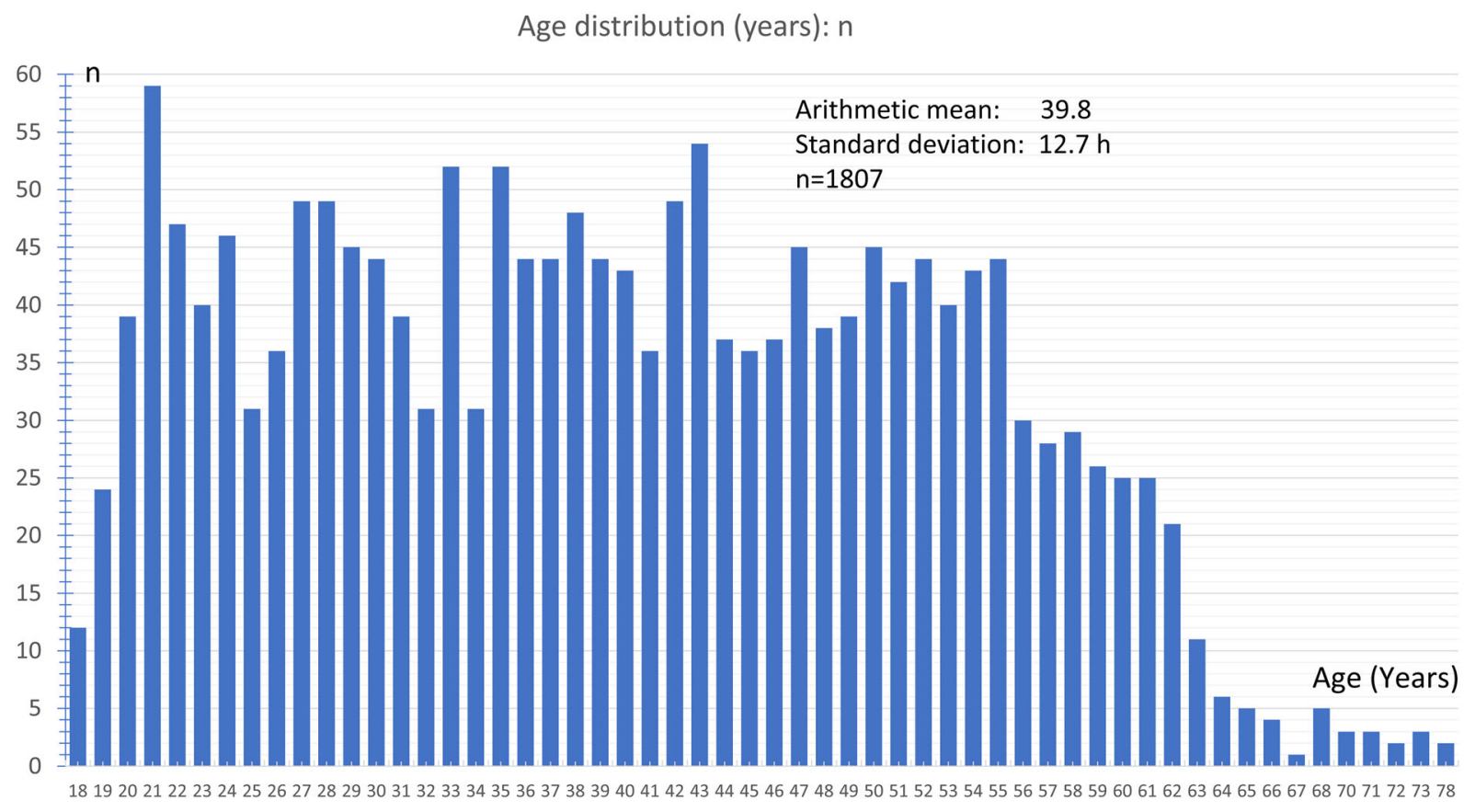

Fig. 1 Age distribution (years) of participants 
Headache after other vaccinations

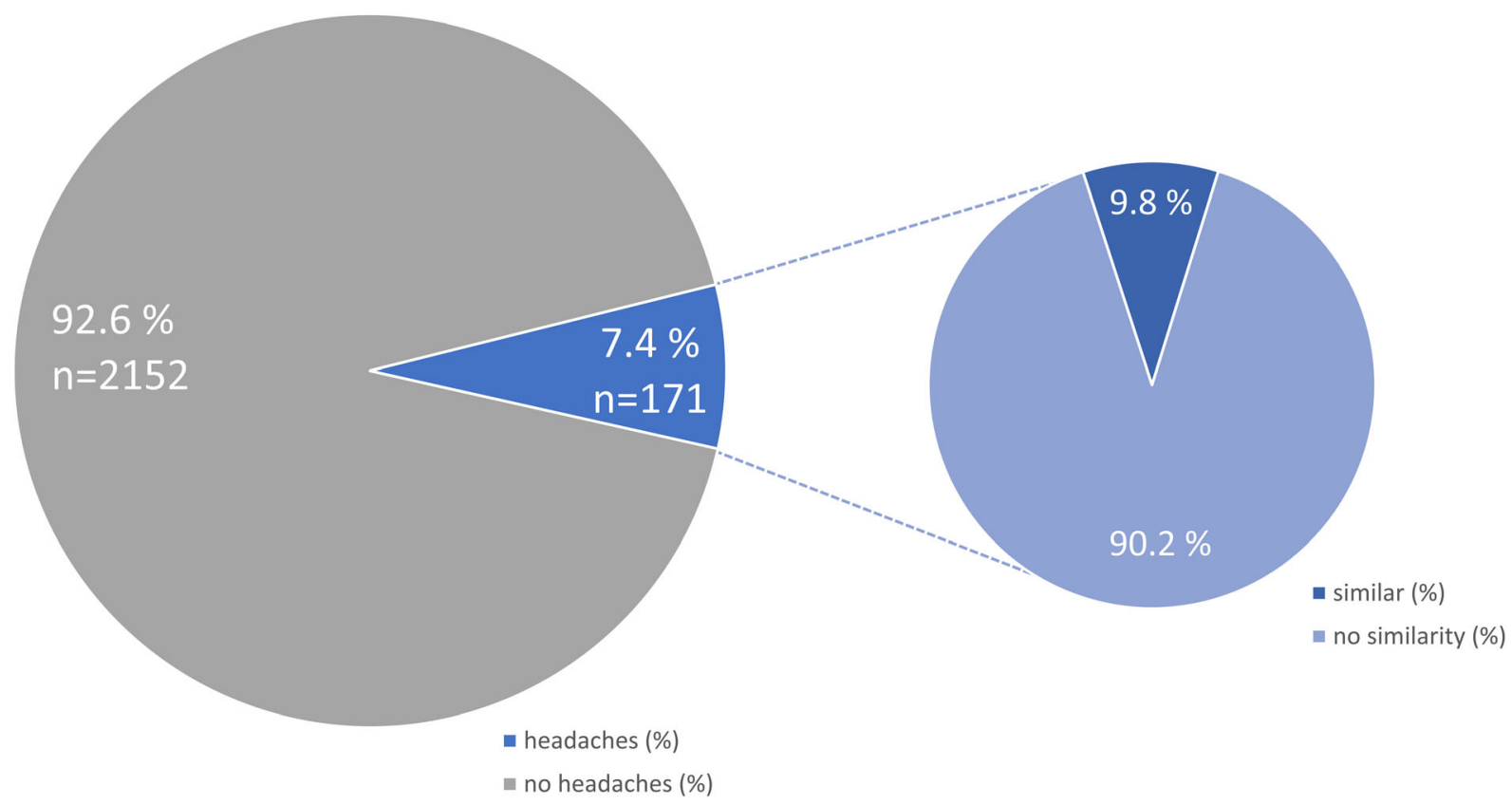

Fig. 2 Relative frequency distribution of headaches after previous vaccinations

History of other headache disorders: frequency distribution (\%)

\section{Headache similar to other vaccinations}

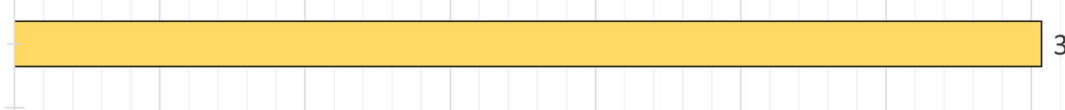

35.35

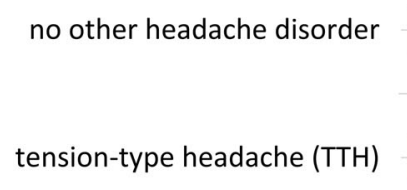$$
+
$$

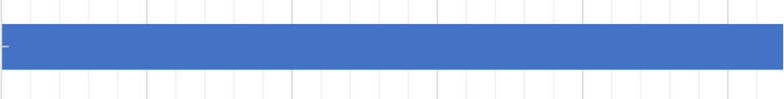

26.9

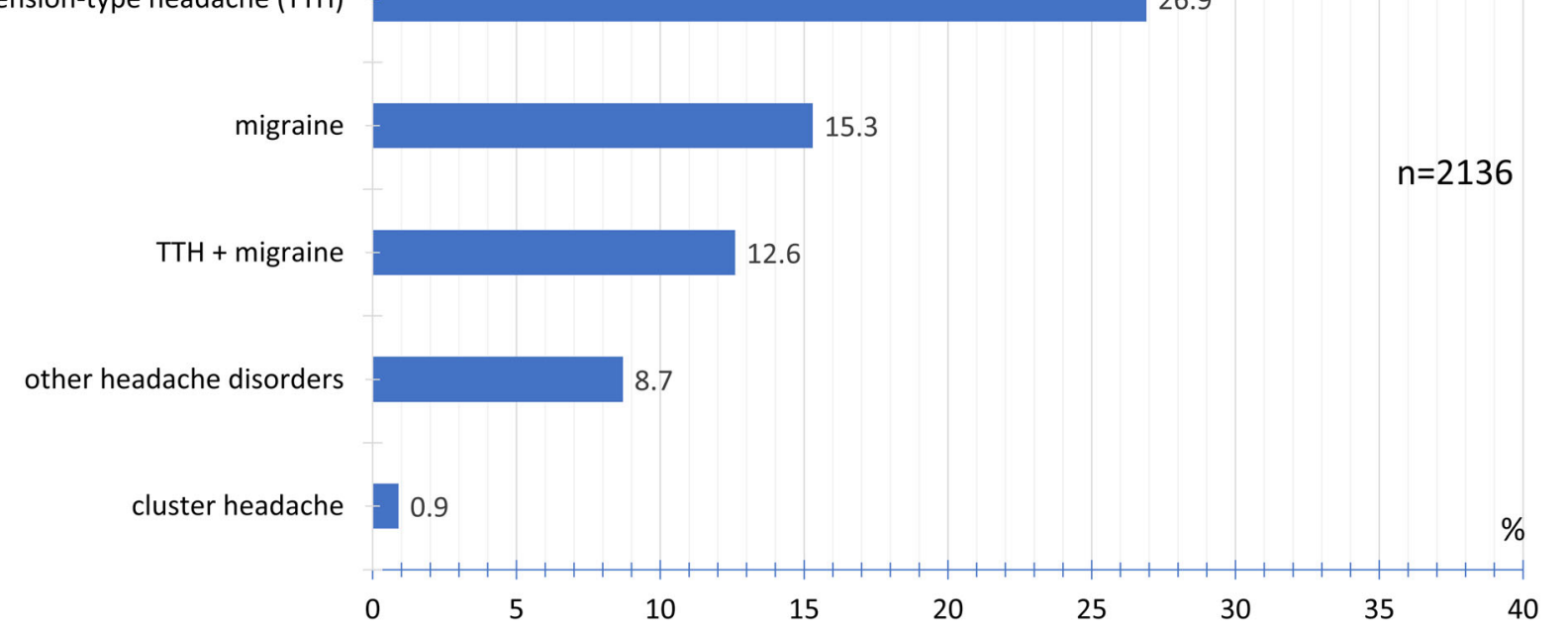

Fig. 3 Frequency distribution of history of other headache disorders 
Comorbid disease: frequency distribution (\%)

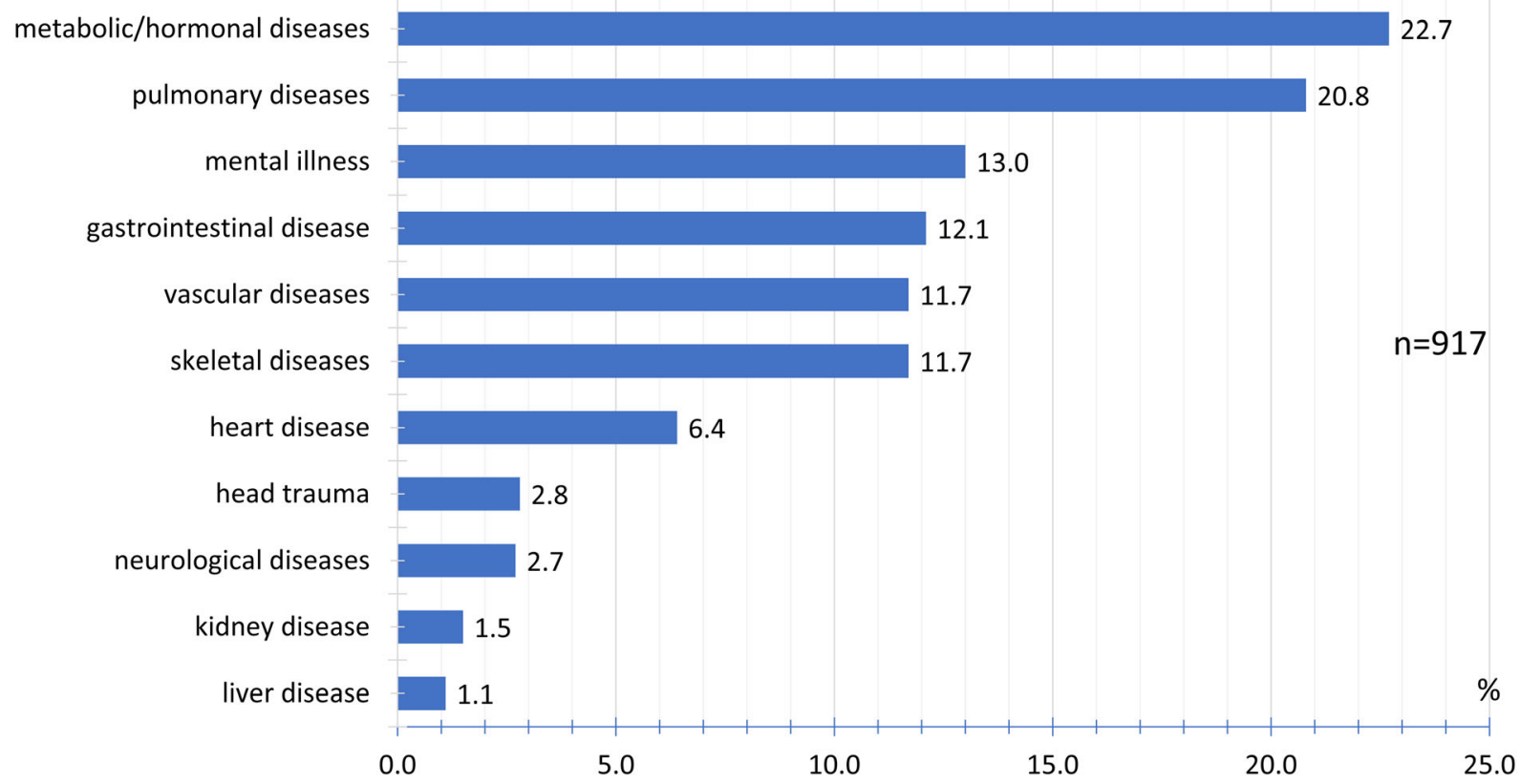

Fig. 4 Frequency distribution of comorbid diseases

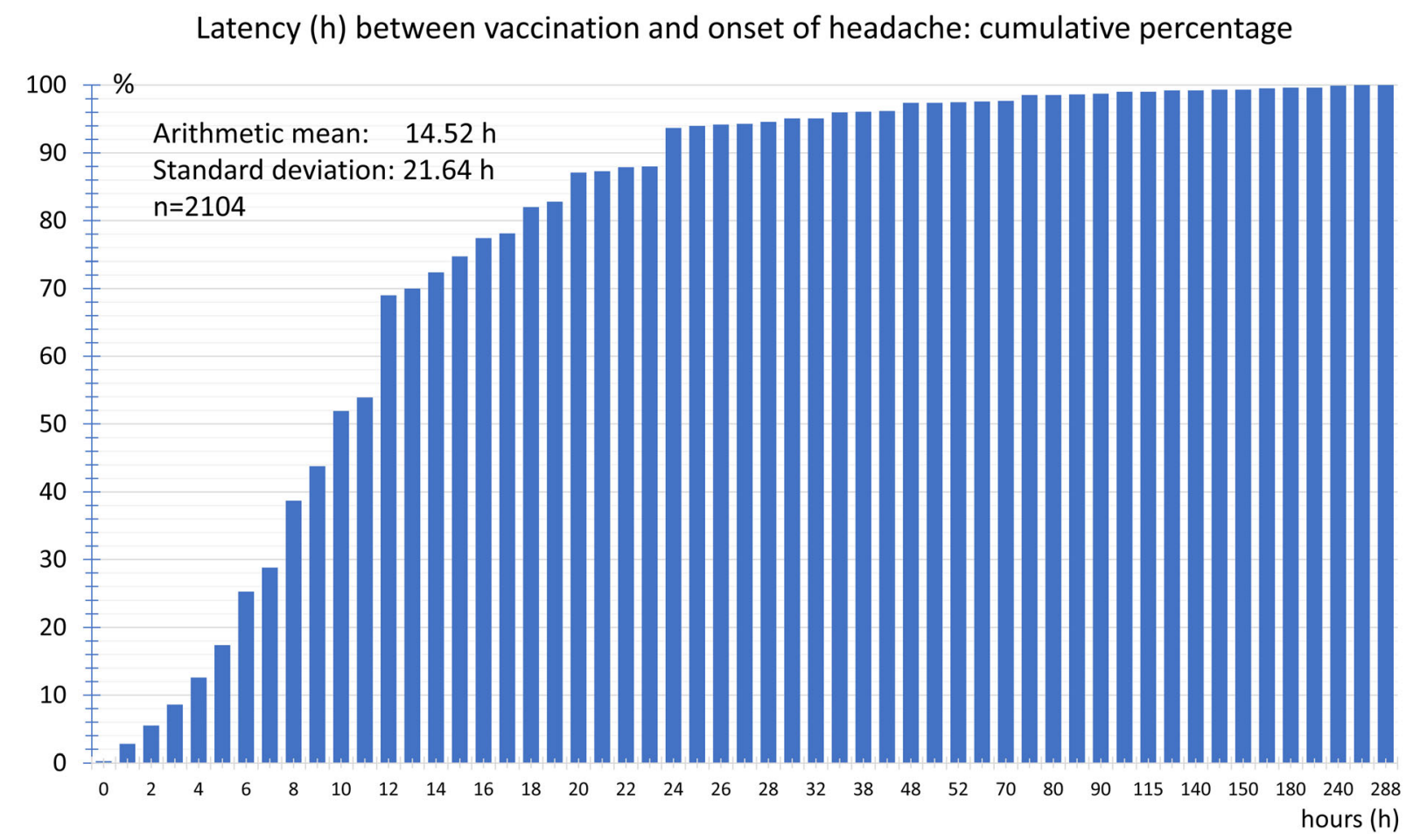

Fig. 5 Cumulative frequency distribution of latency (h) between vaccination and onset of headache 
Duration (h) of headache attributed to Covid-19 vaccination: cumulative

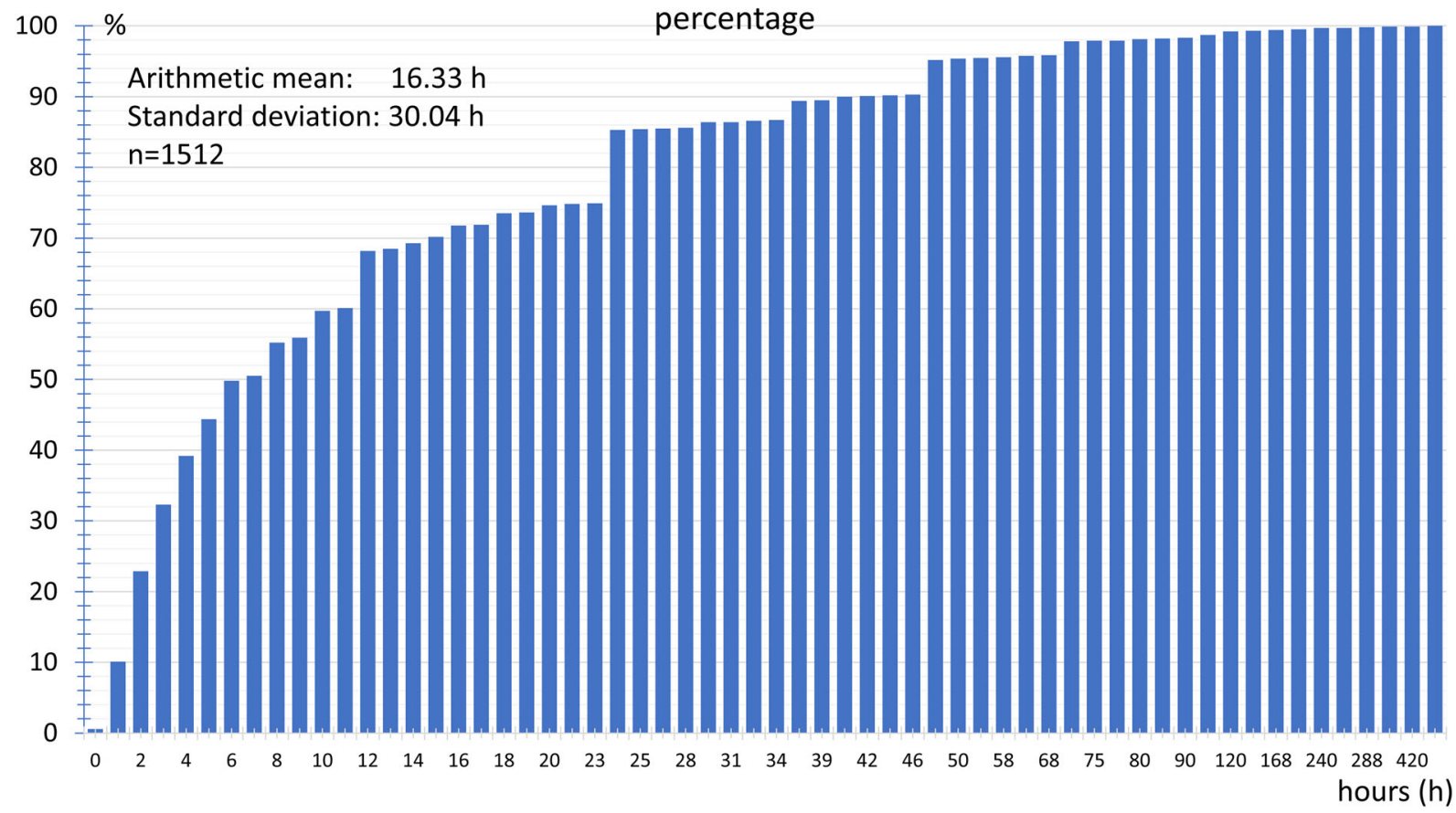

Fig. 6 Cumulative frequency distribution of duration (h) of headache attributed to COVID-19 vaccination

The headache duration was $16.3 \pm 30.4 \mathrm{~h}$ on average. In $50 \%$ of the vaccinees the headache duration was less than $6 \mathrm{~h}$, and in $74.9 \%$, it was less than $22 \mathrm{~h}$. The headache lasted longer than $48 \mathrm{~h}$ in just $4.8 \%$ of the participants. The longest headache duration reported in a single case was $504 \mathrm{~h}$ (Fig. 6).

Overall, $67.4 \%$ of participants indicated that the headache occurred continuously as a single episode without interruption; $32.6 \%$ reported that the headache occurred in multiple phases.

\section{Headache Location and Radiation}

The headache was most frequently located in the forehead area (40.0\% left, 39.7\% right) followed by the temple region (30.4\% left, $31.4 \%$ right) and the back of the head $(24.1 \%$ left, $24.6 \%$ right). Retro-orbital pain was reported by $24.7 \%$. Pain on the top of the skull was indicated by $21.6 \%$, on the left side of the neck by $17.8 \%$, and on the right side by $19.6 \%$ (Fig. 7).

A bilateral headache occurred in $75.8 \%$ of the participants. A non-varying unilateral pain was indicated by $17.2 \%$ of the participants. An alternating one-sided headache was reported by $7.0 \%$ of the participants (Fig. 8).

No radiation of pain was experienced by $56.6 \%$ of the participants, pain radiating to the neck and shoulder by $26.6 \%$, and to the forehead and temples by $16.7 \%$ (Fig. 9 ).

\section{Headache Character}

Overall, $50.4 \%$ of the participants indicated a pressing and $37.7 \%$ a dull pain character (Fig. 10). Less commonly, $18.0 \%$ of the patients experienced a pulsating pain (wave-like fluctuations of pain with every heartbeat) and $17.3 \%$ a stinging pain (repeated short stabs of pain) character. A throbbing pain (pulsing, beating sensation happening over and over again) was reported by $16.28 \%$, a pounding pain by $14.4 \%$, and a pulling pain by $13.1 \%$ of the participants. Other pain characters were reported by less than $10 \%$ of the participants. 


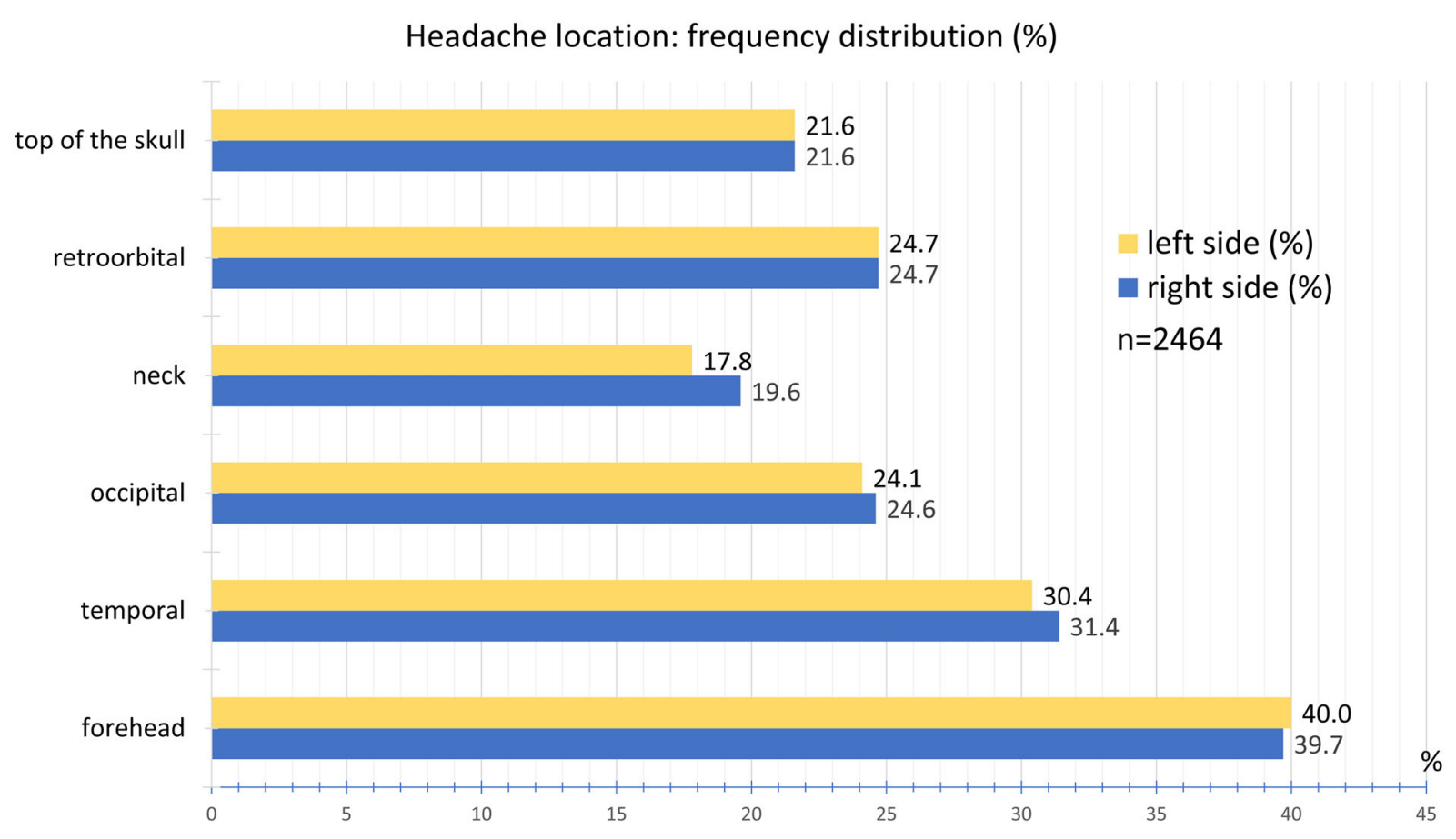

Fig. 7 Frequency distribution of headache location

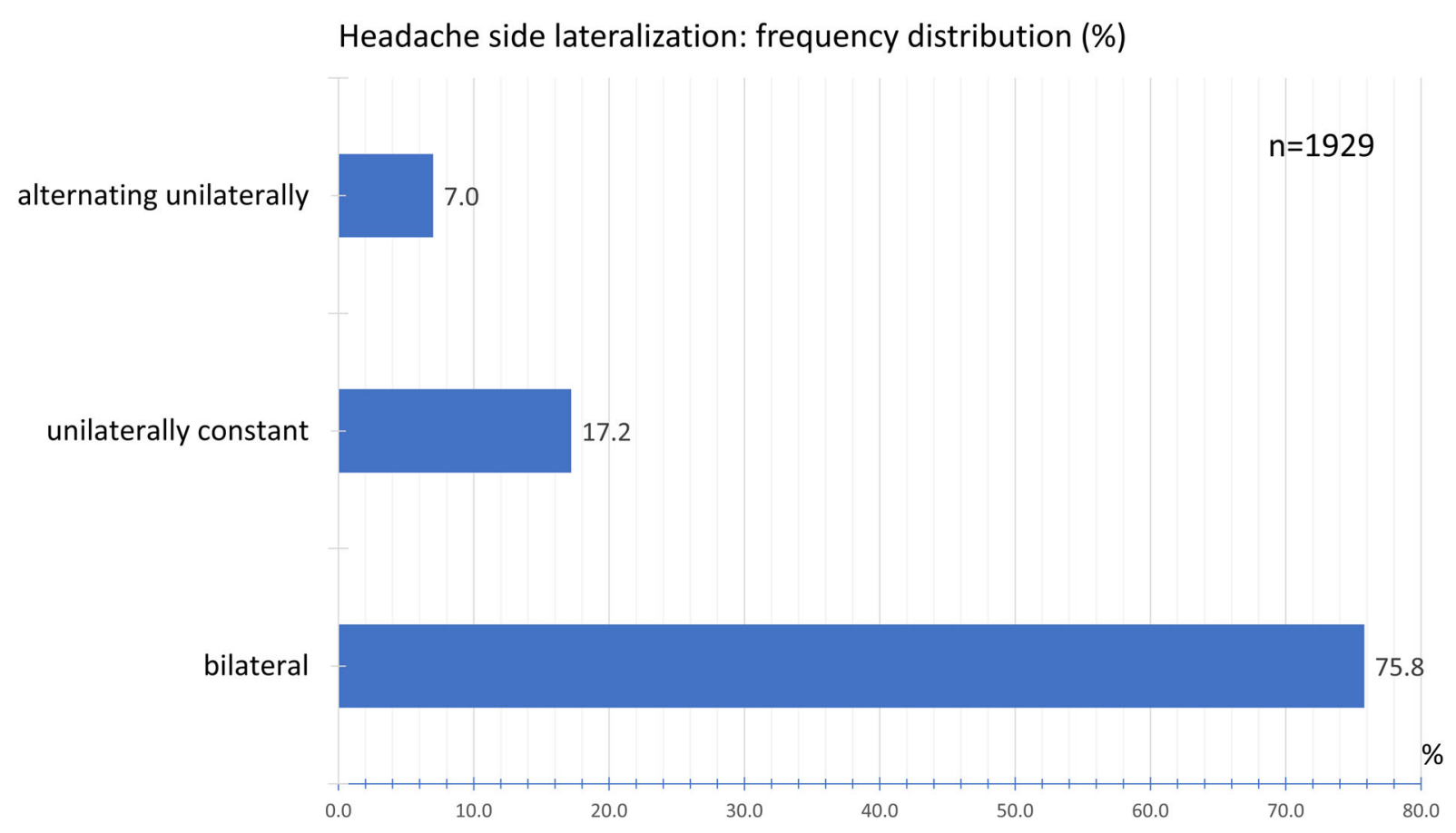

Fig. 8 Frequency distribution of headache side lateralization 


\section{Radiation of pain: frequency (\%)}

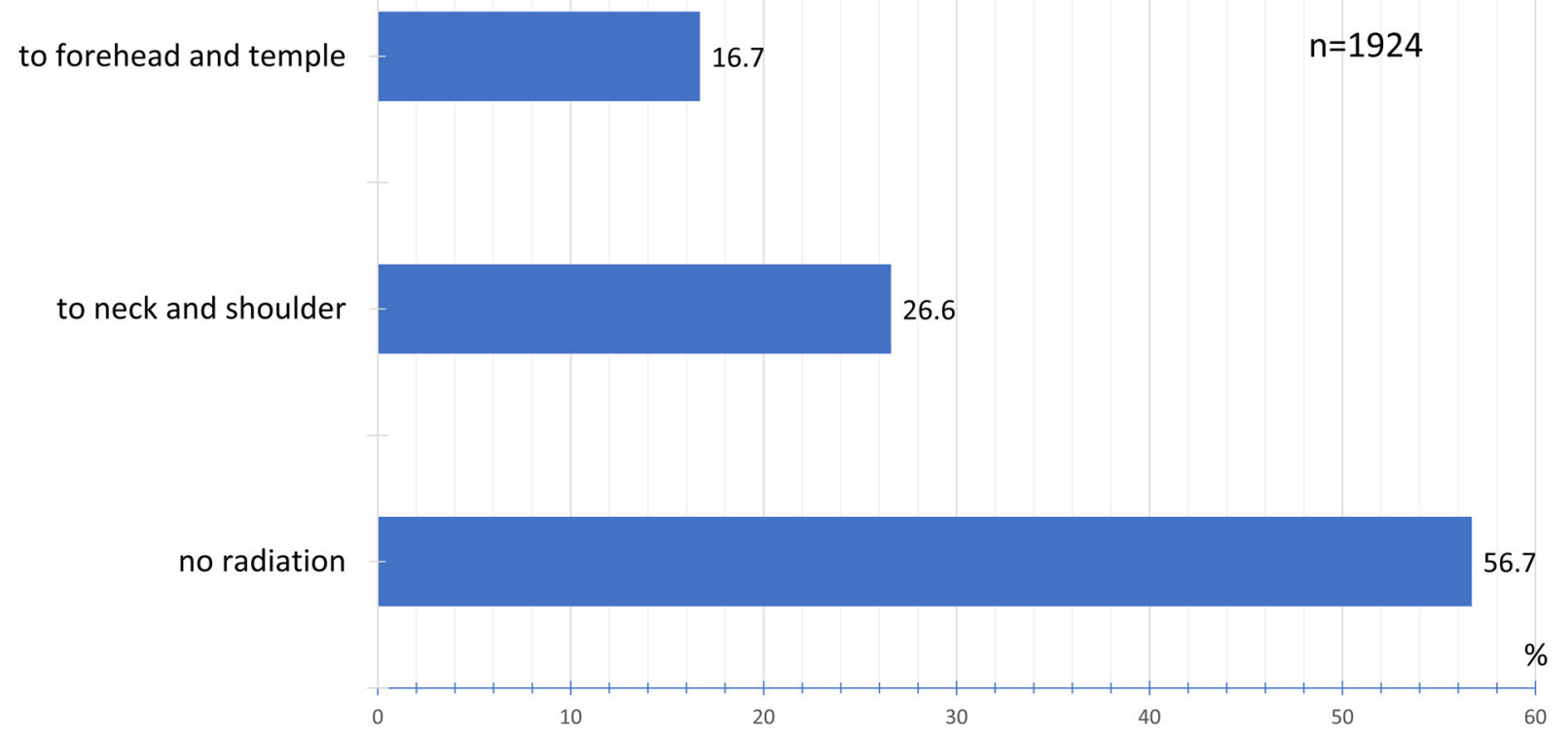

Fig. 9 Frequency distribution of radiation of pain

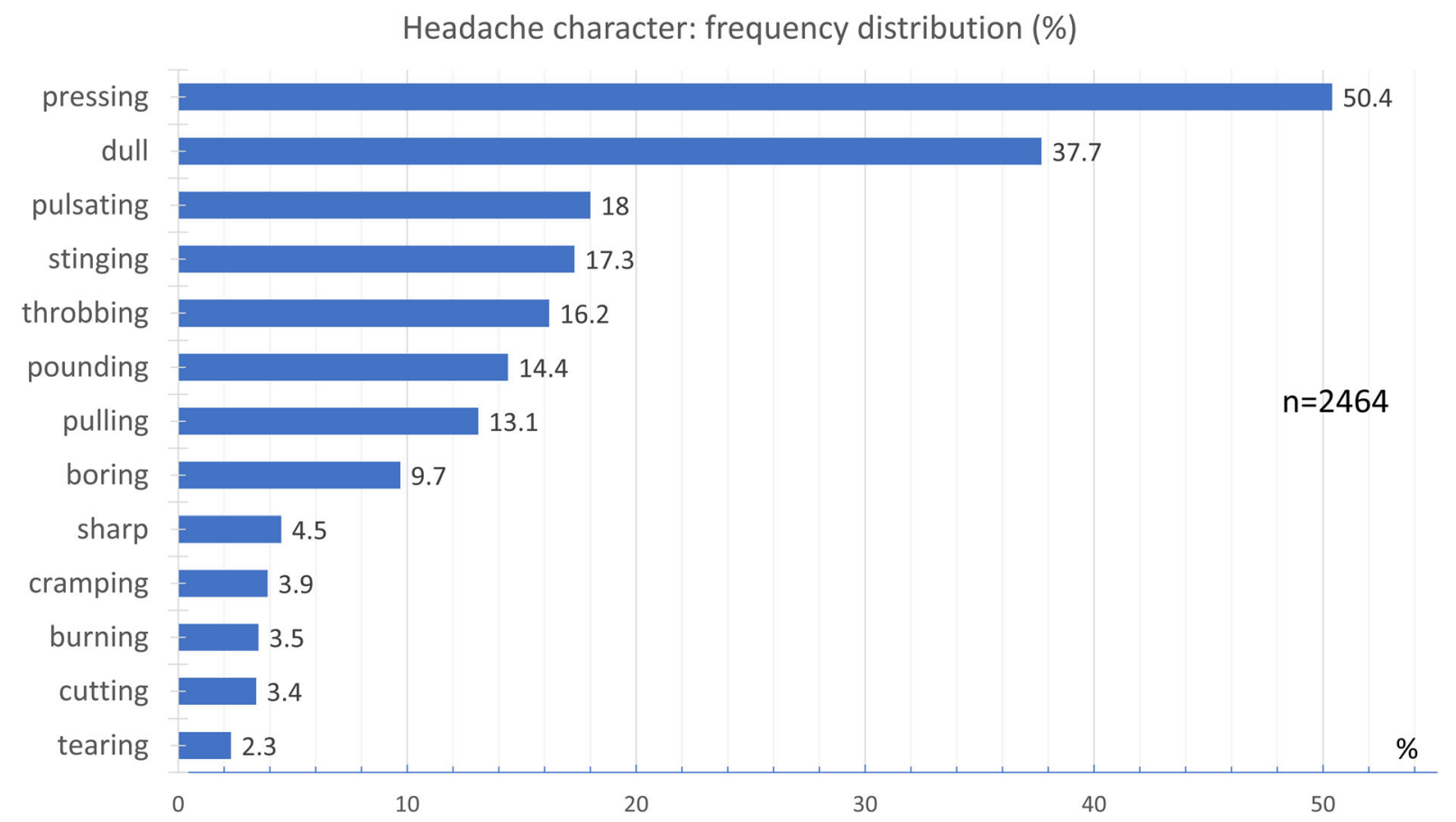

Fig. 10 Frequency distribution of headache character 


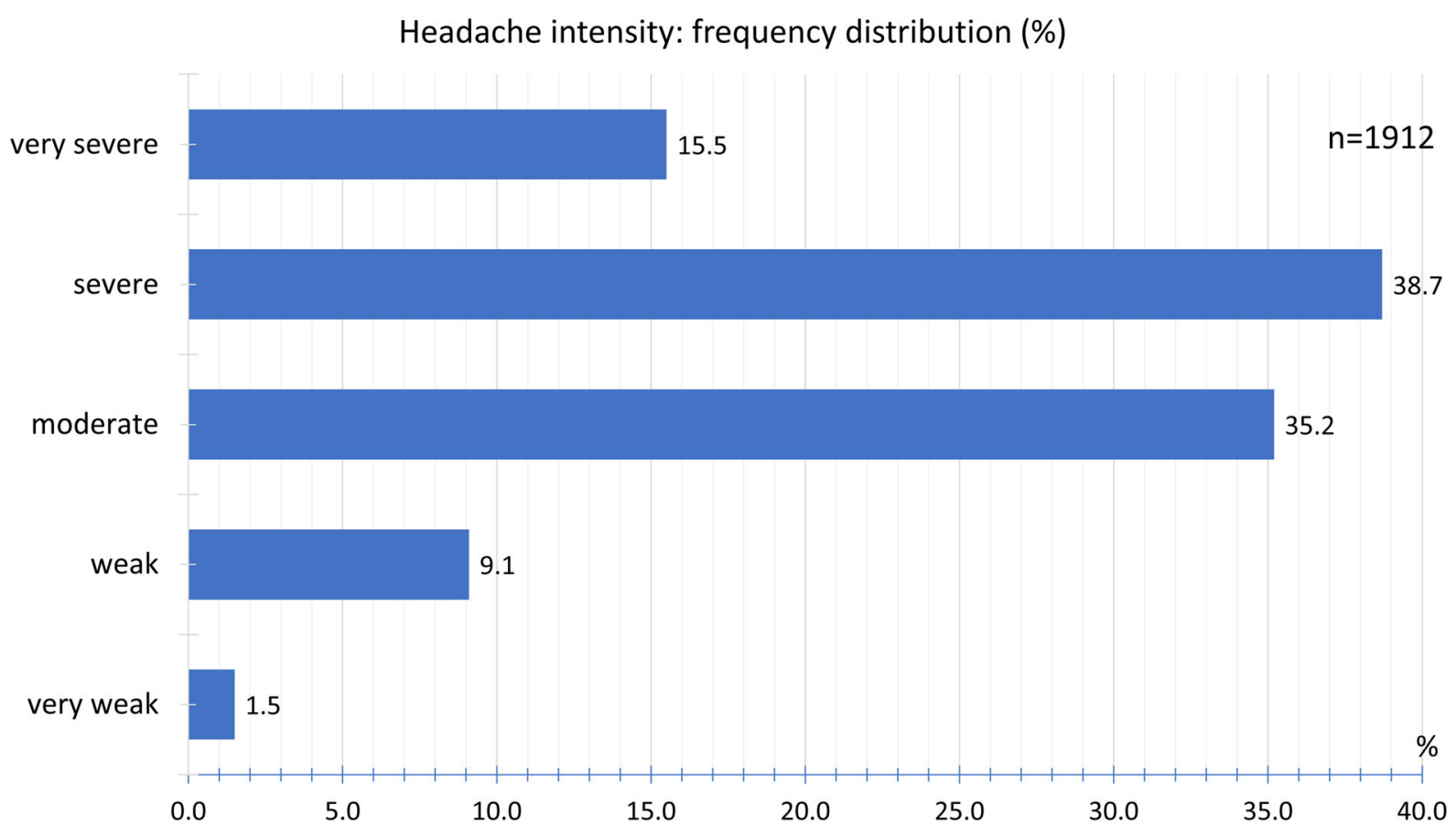

Fig. 11 Frequency distribution of headache intensity

Effect of routine physical activity on headache: frequency distribution (\%)

routine activity without effect

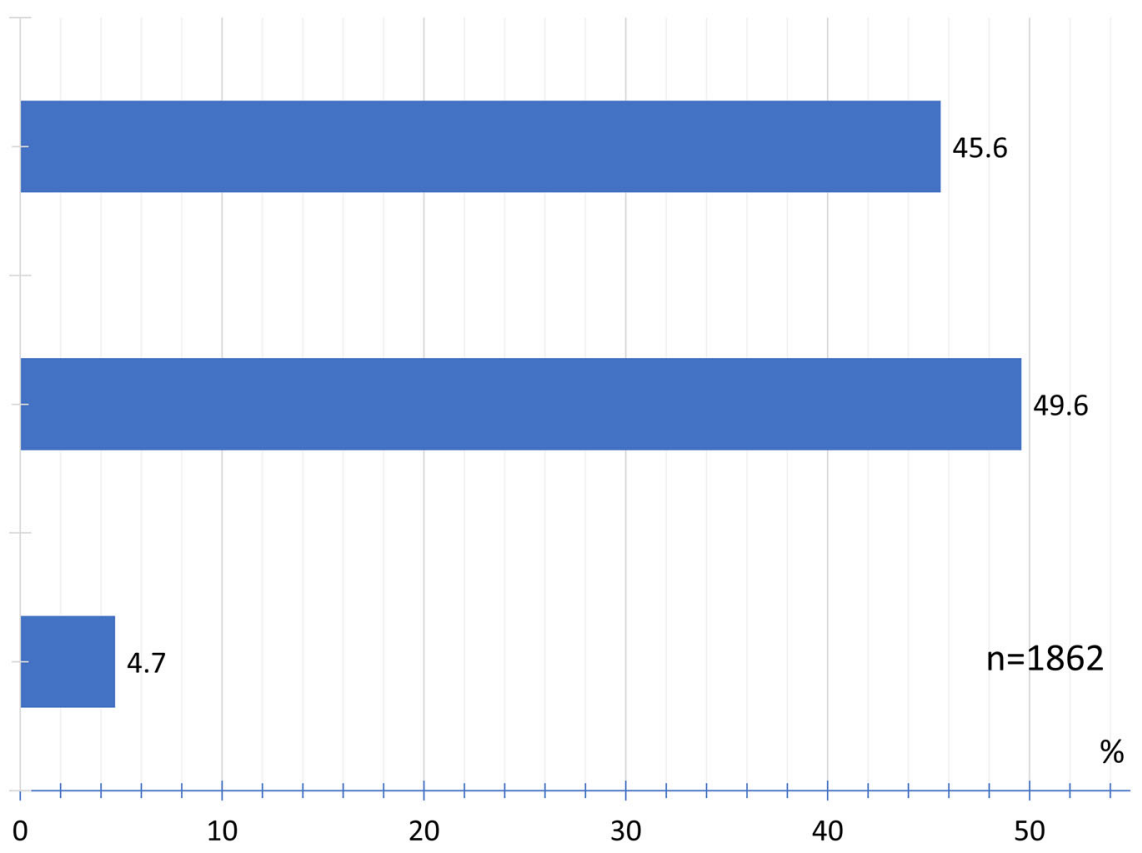

Fig. 12 Frequency distribution of effect of routine physical activity on headache 


\section{Headache Intensity}

After COVID-19 vaccination with the ChAdOx1 nCoV-19 (AZD1222) vaccine, the headache intensity was documented as severe by $38.7 \%$ of the participants, moderate by $35.2 \%$, and very severe by $15.5 \%$. A mild headache was documented by $9.1 \%$ and a very mild headache by $1.5 \%$ of the participants (Fig. 11).

Overall, $45.6 \%$ of the participants found that routine physical activity did not affect headache intensity; $49.6 \%$ indicated that routine physical activity did indeed worsen the headache, while $4.7 \%$ found that routine physical activity actually relieved the headache (Fig. 12).

\section{Accompanying Symptoms}

We evaluated migraine-typical accompanying symptoms and other accompanying symptoms separately. Sensitivity to noise $(33.4 \%)$, sensitivity to light $(31.8 \%)$, and nausea $(28.1 \%)$ were the most frequently reported symptoms typical of migraine. Loss of appetite (24.2\%), hypersensitivity to smell (3.7\%), and vomiting (4.0\%) were less common (Fig. 13).

The most frequently reported other accompanying symptoms were fatigue (44.8\%), chills (36.1\%), exhaustion (34.9\%), and fever (30.4\%) (Fig. 14). With a frequency between $10.6 \%$ and $28.2 \%$, the participants experienced weakness, joint pain, dizziness, neck pain, increased perspiration, poor concentration, and reddening of the vaccination site. Sensitivity to touch, muscle pain, unsteadiness when walking, neck stiffness, irritability, anxiety, pale skin, tearfulness, and visual disturbances were experienced with a frequency between $5 \%$ and $10 \%$. Other accompanying symptoms experienced by less than 5\% are listed in Fig. 14.

\section{Association with Pre-existing Headache Disorders}

We also investigated the effect of pre-existing headache illnesses on quantitative parameters of headaches after COVID-19 vaccination to uncover a possible connection between pre-existing headache disorders and headache occurring after COVID-19 vaccination (Table 2). In

Migraine-like accompanying symptoms: frequency distribution (\%)

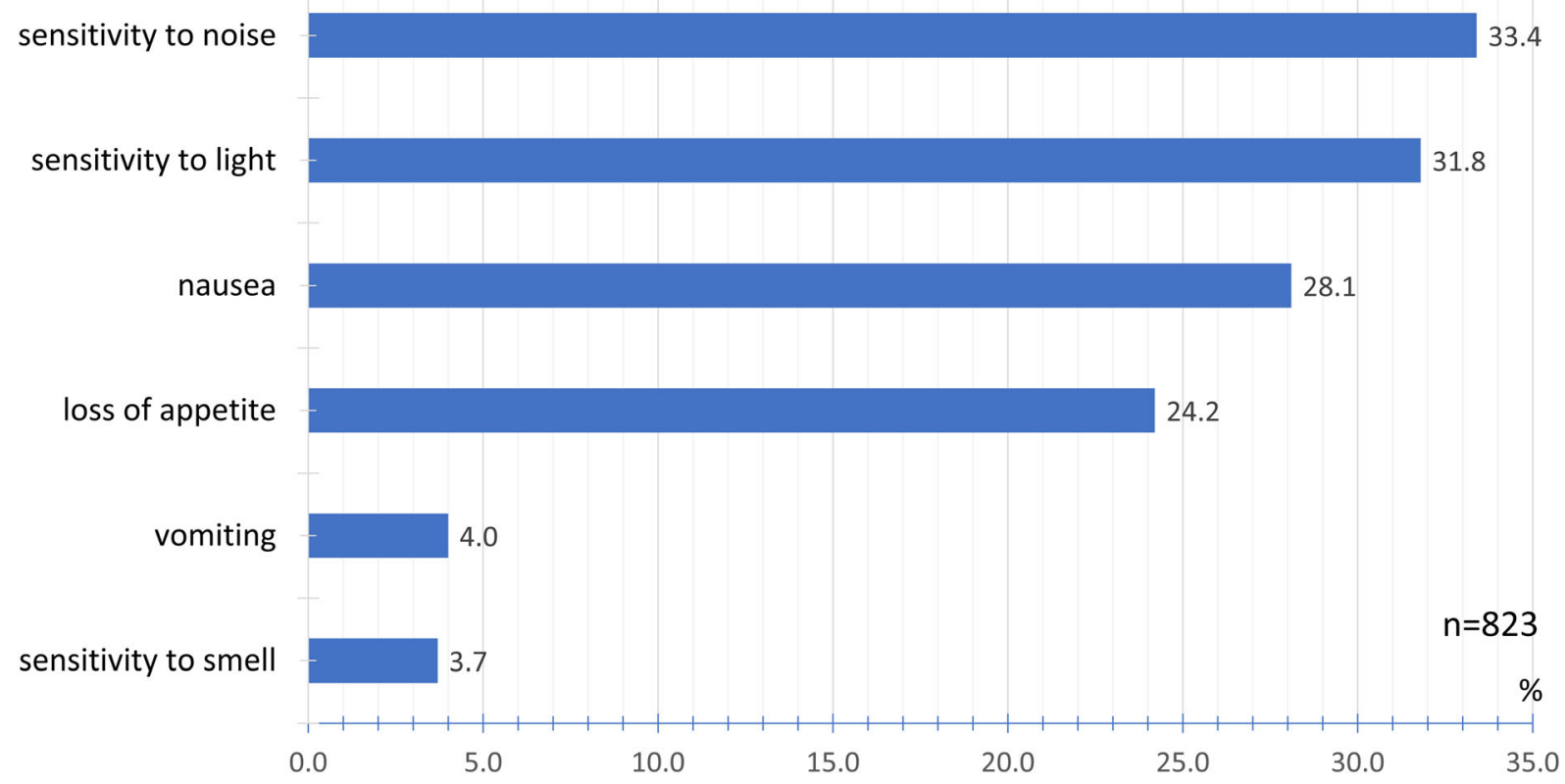

Fig. 13 Frequency distribution of migraine-like accompanying symptoms 


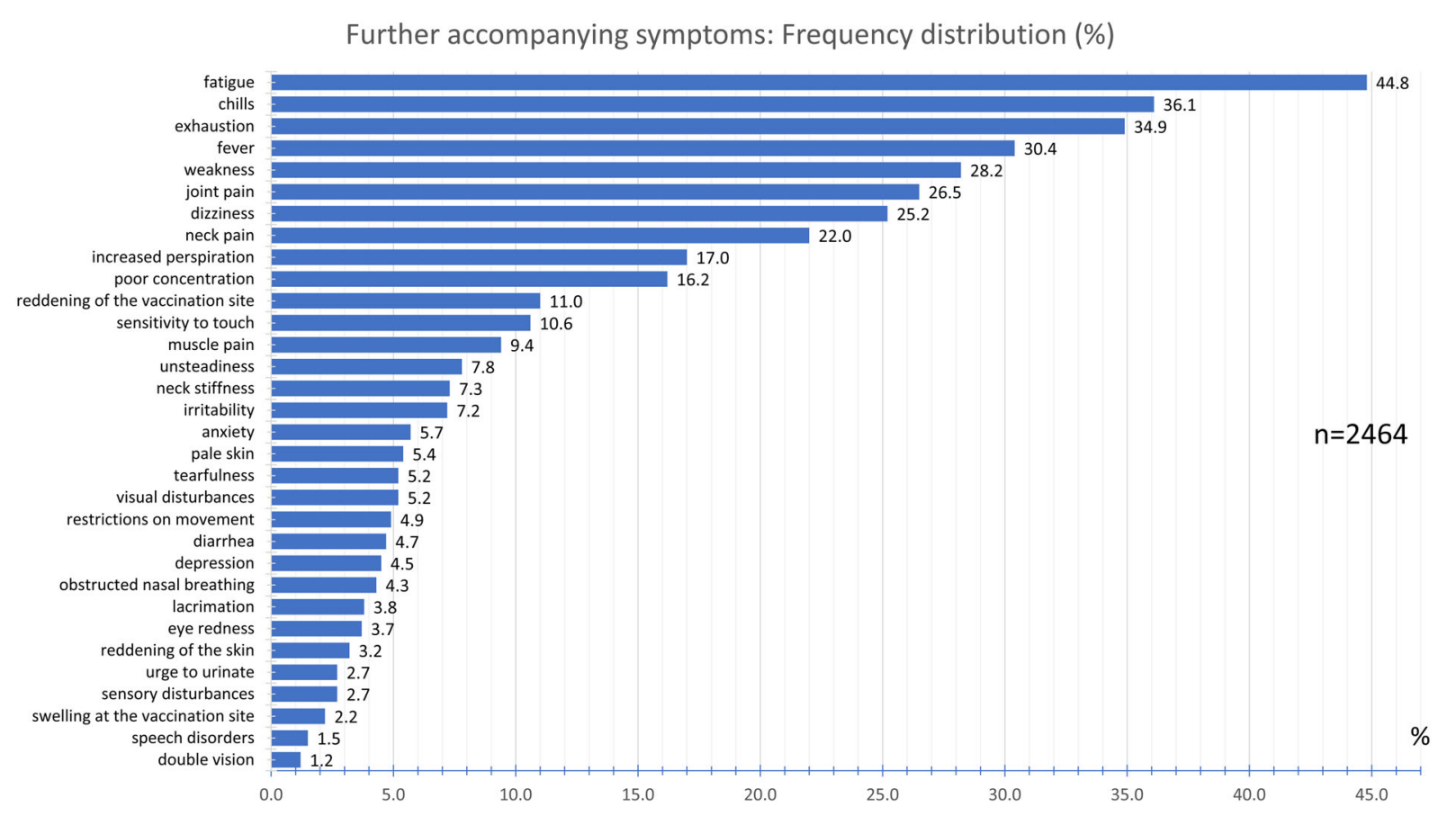

Fig. 14 Frequency distribution of further accompanying symptoms

participants with a history of migraine, there was no effect on the time between the vaccination and the onset of the headache compared to participants who had no primary headache. However, headache duration after COVID-19 vaccination was significantly longer in patients with a history of migraine than in participants without primary headache $(20.9 \pm 32.6$ vs. $13.0 \pm 18.5 \mathrm{~h} ; p=0.002$ ). Furthermore, patients with migraine $(3.7 \pm 0.8$ vs. $3.2 \pm 0.9$; $p<0.001)$ and tension-type headache $(3.5 \pm 0.8$ vs. $3.2 \pm 0.9 ; p<0.010)$ reported a significantly higher headache pain intensity on the verbal rating scale (VRS 0-5) after COVID-19 vaccination compared to participants who had no history of migraine.

Participants with a history of tension-type headache or cluster headache showed no difference in the time interval between vaccination and the onset of headache as well as the duration of the headache after COVID-19 vaccination compared to participants without primary headache (Table 2 ).

\section{Gender Differences}

There were no significant differences in the latency between vaccination and onset of headache and the duration of the headache between women and men (Table 3). The same was true regarding the headache intensity (VRS 0-5) attributed to COVID-19 vaccination $(3.6 \pm 0.9$ in women vs $3.2 \pm 0.8$ in men; $p<0.000)$.

\section{Age Effect}

To analyze an age effect, we split up participants into a group of up to 55 years of age and older than 55 years of age. We found no significant differences regarding the interval between vaccination and onset of the headache, as well as the duration of the headache (Table 4 ) between these two age groups. However, the headache intensity was significantly higher in vaccinated people under 55 years of age than 55 years of age and above $(3.2 \pm 0.9$ vs. $3.6 \pm 0.8$; $p<0.000)$. 
Table 2 Comparison of patients with pre-existing primary headaches (migraine, tension-type headache, or cluster headache) with patients without pre-existing primary headaches with regard to quantitative parameters of headaches attributed to COVID-19 vaccination with the ChAdOx1 $\mathrm{nCoV}-19$ (AZD1222) vaccine

\begin{tabular}{lllll}
\hline & Migraine & $\begin{array}{l}\text { Tension-type } \\
\text { headache }\end{array}$ & $\begin{array}{l}\text { Cluster } \\
\text { headache }\end{array}$ & $\begin{array}{l}\text { No primary } \\
\text { headaches }\end{array}$ \\
\hline $\begin{array}{l}\text { Latency between vaccination and onset of headache } \\
\text { (hours) }\end{array}$ & $14.3 \pm 20.6$ & $14.2 \pm 20.0$ & $9.4 \pm 4.5$ & $14.8 \pm 22.9$ \\
& $n=274$ & $n=497$ & $n=16$ & $n=1060$ \\
& $p=0.719$ & $p=0.582$ & $p=0.343$ & \\
$\begin{array}{l}\text { Duration of headache attributed to COVID-19 } \\
\text { vaccination (hours) }\end{array}$ & $20.9 \pm 32.6$ & $16.8 \pm 35.2$ & $22.0 \pm 35.6$ & $13.0 \pm 18.5$ \\
& $n=201$ & $n=361$ & $n=11$ & $n=490$ \\
& $p=0.002$ & $p=0.159$ & $p=0.333$ & \\
$\begin{array}{l}\text { Intensity of headache attributed to COVID-19 } \\
\text { vaccination (VRS 0-5) }\end{array}$ & $3.7 \pm 0.8$ & $3.5 \pm 0.8$ & $3.6 \pm 0.9$ & $3.2 \pm 0.9$ \\
& $n=247$ & $n=501$ & $n=16$ & $n=602$ \\
\hline
\end{tabular}

Arithmetic mean and standard deviation. Statistical analysis using $t$ test

\section{Treatment}

Regarding acute headache medication, $53.1 \%$ of the participants used paracetamol, followed by ibuprofen (50.7\%) and metamizole (12.0\%). Other medications used are listed in Fig. 15.

Participants taking multiple drugs were asked to rank for the most effective drug. Figure 16 shows the relative frequency with which an active ingredient was rated as the most effective drug. Accordingly, acetylsalicylic acid was most frequently named as the most effective treatment option by $46.2 \%$.

\section{DISCUSSION}

Headaches attributed to COVID-19 vaccination with the ChAdOx1 nCoV-19 (AZD1222) vaccine show an extensive complex of symptoms with concise clinical characteristics. The specific set of accompanying symptoms along with the temporal and spatial headache characteristics characterize a unique headache phenotype for headaches attributed to COVID-19 vaccination. This phenotype is different from that of primary headaches. These headaches occur with similar symptoms across all age groups. Less than $8 \%$ of

Table 3 Group comparison of women and men with regard to quantitative parameters of headaches attributed to COVID19 vaccination with the $\mathrm{ChAdOx} 1 \mathrm{nCoV}-19$ (AZD1222) vaccine

\begin{tabular}{llll}
\hline & Women & Men & $\boldsymbol{t}$ test \\
\hline Latency between vaccination and onset of headache (hours) & $14.3 \pm 20.9$ & $15.6 \pm 23.8$ & $p=0.342$ \\
& $n=1518$ & $n=274$ & \\
Duration of headache attributed to COVID-19 vaccination (hours) & $17.3 \pm 33.4$ & $13.7 \pm 16.6$ & $p=0.130$ \\
& $n=1086$ & $n=207$ & \\
Intensity of headache attributed to COVID-19 vaccination (VRS 0-5) & $3.6 \pm 0.9$ & $3.2 \pm 0.8$ & $p<0.001$ \\
& $n=1533$ & $n=276$ & \\
\hline
\end{tabular}

Arithmetic mean and standard deviation. Statistical analysis using $t$ test 
Table 4 Age group comparison of participants aged $\geq 55$ years and $<55$ years with regard to quantitative parameters of headaches attributed to COVID-19 vaccination with the ChAdOx1 nCoV-19 (AZD1222) vaccine

\begin{tabular}{llll}
\hline & $\mathbf{2 5}$ & $<\mathbf{5 5}$ & $\boldsymbol{t}$ test \\
\hline Latency between vaccination and onset of headache (hours) & $15.4 \pm 19.9$ & $14.3 \pm 21.7$ & $p=0.473$ \\
& $n=271$ & $n=1519$ & \\
Duration of headache attributed to COVID-19 vaccination (hours) & $15.7 \pm 22.4$ & $16.9 \pm 32.7$ & $p=0.609$ \\
& $n=191$ & $n=1101$ & \\
Intensity of headache attributed to COVID-19 vaccination (VRS 0-5) & $3.2 \pm 0.9$ & $3.6 \pm 0.8$ & $p<0.001$ \\
& $n=273$ & $n=1533$ & \\
\hline
\end{tabular}

Arithmetic mean and standard deviation. Statistical analysis using $t$ test

those affected experienced headaches resulting from previous vaccinations. And of these, over 90\% report that the headache after COVID-19 vaccination is different from the headache following previous other vaccinations. On average, headache attributed to COVID-19 vaccination occurs $15 \mathrm{~h}$ after vaccination with a duration of $17 \mathrm{~h}$. In around two-thirds the headache lasts between 1 and $12 \mathrm{~h}$. Over $67 \%$ experience a monophasic headache. The headache occurs bilaterally in more than $75 \%$, the main localization being the forehead, temples, back of the head, and retro-orbital region. They do not commonly radiate to other regions. The pain character is most commonly described as pressing and dull, with pain intensity being most often moderate to severe. Routine physical activity can aggravate the pain. The most frequent accompanying symptoms are fatigue, chills, exhaustion, sensitivity to noise, and sensitivity to light. In women, the intensity of headache is significantly greater than in men. People younger than 55 years of age have significantly higher headache intensities than those who are vaccinated aged 55 or above.

In the clinical approval studies, the use of paracetamol was recommended prophylactically prior to vaccination in all trials (except in study COV005; it was introduced as an amendment during study COV001 [14]. The vaccinees were recommended to continue with $1000 \mathrm{mg}$ of paracetamol in 6-h intervals for $24 \mathrm{~h}$ to reduce vaccine-induced side effects. The COV001 study analyzed the effect of paracetamol on immunogenicity using a standardized ELISA on participants [19]. When study participants who received paracetamol were compared with those who did not, differences in the generation of anti-S responses were not observed. However, it is possible that the headache phenotype was mitigated in these studies by the prophylactic administration of paracetamol. In the open application within the scope of this study, no prophylactic administration of paracetamol took place. In Germany, the preventive use of paracetamol was not recommended. It is also not included in the package insert. The headache phenotype recorded here can therefore provide a more realistic, unmasked picture.

The uncovered headache phenotype in our study is neither that of migraine nor that of a tension-type headache. It may be possible that clinical symptoms of these two primary headaches are included in the questionnaire reports and overlap with the headache phenotype attributed to COVID-19 vaccination. However, the described symptom complex of headache attributed to COVID-19 vaccination with the ChAdOx1 nCoV-19 (AZD1222) differs markedly from the aforementioned primary headaches.

The International Classification of Headache Disorders [25] lists headaches attributed to intracranial and systemic infections, either bacterial, viral, fungal, or parasitic. Headaches attributed to systemic viral infection are also described. A specific headache phenotype, however, is not described in these cases. 


\section{Relative frequency distribution of medication used (\%)}

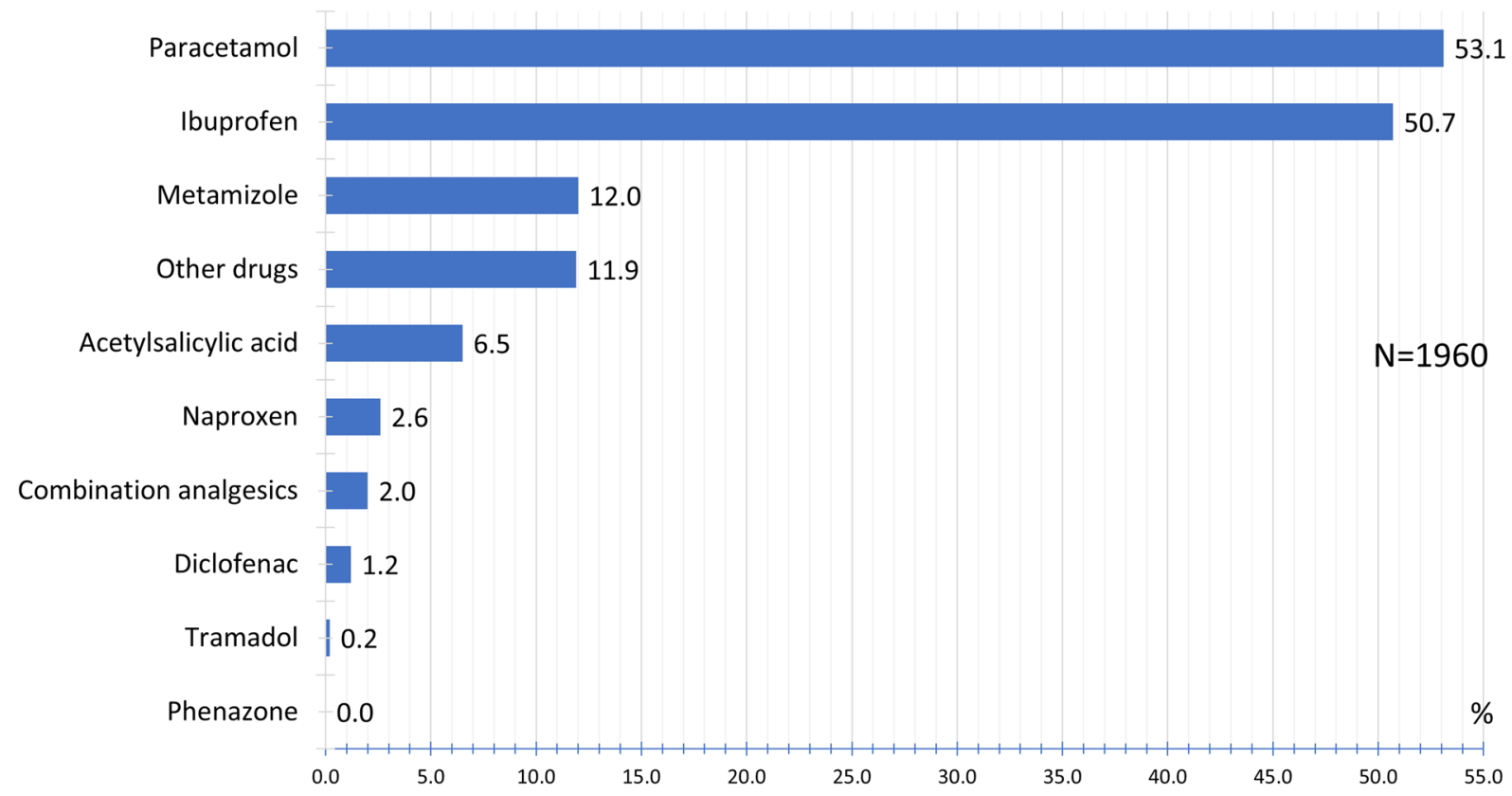

Fig. 15 Frequency distribution of medication used

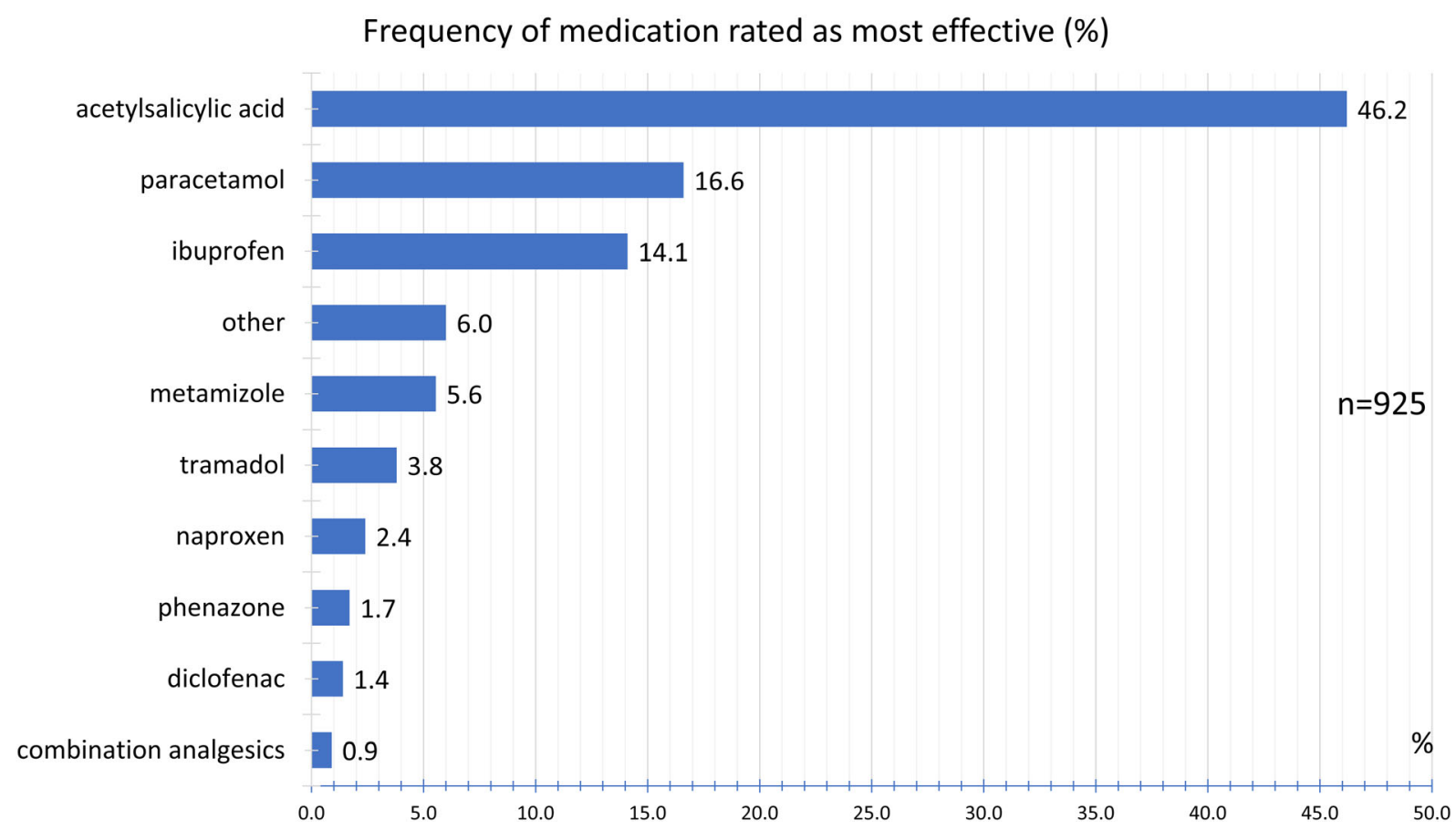

Fig. 16 Frequency of medication rated as most effective 
Table 5 Proposal for diagnostic criteria of headaches attributed to COVID-19 vaccination with the ChAdOx1 nCoV-19 (AZD1222) vaccine

\section{Acute headache attributed to Covid-19 vaccination with the ChAdOx1 nCoV-19 (AZD1222) vaccine}

Diagnostic criteria:

A. Any new headache fulfilling at least three of the following five characteristics:

1. bilateral localisation

2. pressing or dull headache character

3. moderate to severe intensity

4. Sensitivity to noise and/or light

5. Routine physical activity does not alleviate

B. Vaccination with the ChAdOx1 nCoV-19 (AZD1222) vaccine has been carried out

C. Evidence of causation demonstrated by at least two of the following:

1. headache developed within $24 \mathrm{~h}$ after vaccination

2. headache has developed in close temporal relation to other symptoms and/or clinical signs of the vaccination at least two of the following

$$
\begin{aligned}
& \text { fatigue } \\
& \text { chills } \\
& \text { exhaustion } \\
& \text { fever }
\end{aligned}
$$

3. headache has significantly improved in parallel with stabilization or improvement of other symptoms and/or clinical signs of the vaccination.

D. Either of the following:

1. headache has resolved within $72 \mathrm{~h}$

2. headache has not yet resolved but $72 \mathrm{~h}$ have not yet passed

E. Not better accounted for by another ICHD-3 diagnosis.

\section{Persistent headache attributed to Covid-19 vaccination with the ChAdOx1 nCoV-19 (AZD1222) vaccine}

Diagnostic criteria:

A. Headache previously diagnosed as acute headache attributed to Covid-19 vaccination with the ChAdOx1 nCoV-19 (AZD1222) vaccine

B. Headache has persisted for $>72 \mathrm{~h}$ after onset of headache

C. Not better accounted for by another ICHD-3 diagnosis

Headaches after vaccination are not yet listed in the International Classification of Headache Disorders. In particular, no detailed knowledge exists about the form of headaches occurring after vaccination with a single recombinant, replication-deficient chimpanzee adenovirus (ChAdOx1) vector encoding the $\mathrm{S}$ glycoprotein of SARS-CoV-2 in general and specifically with the ChAdOx1 nCoV-19 (AZD1222) vaccine. For the first time, the findings described in this report provide an overview of the phenotype of this headache, which can occur in more than $57 \%$ of the participants after vaccination as the most frequent neurological symptom $[9,14]$. In Table 5, we summarize the results, and we propose diagnostic criteria for acute and persistent 
headaches attributed to COVID-19 vaccination with the ChAdOx1 nCoV-19 (AZD1222) vaccine by analogy to the current ICHD-3 criteria [25], subject to further empirical studies.

Knowledge of these diagnostic criteria is crucial because these headaches may occur in patients who have no other headache disorder. It also allows one to differentiate vaccinationattributed headaches from other spontaneously occurring headache causes. While headaches in relation to a systemic viral infection typically have no specific headache characteristics regarding temporal aspects, pain character, location, and accompanying symptoms, the findings of this study delineate a specific headache phenotype with characteristic accompanying symptoms.

Our findings have several important clinical implications for the differentiation of headache after vaccination with the ChAdOx $1 \mathrm{nCoV}-19$ (AZD1222) vaccine, which can occur in over $57 \%$ of vaccinated persons [14] and headache due to cerebral venous thrombosis (CVT). Headache is by far the most frequent symptom of CVT, present in $80-90 \%$ of cases, and also the most frequent inaugural symptom [25]. These headaches show no specific characteristics, but most often are diffuse, progressive and severe, and associated with other signs of intracranial hypertension. CVT can also mimic other primary and secondary headaches. In over $90 \%$, CVT is associated with focal neurological signs and/or signs of intracranial hypertension, subacute encephalopathy, or cavernous sinus syndrome.

Post-vaccination headaches occur on average within $15 \mathrm{~h}$ and last for $16 \mathrm{~h}$. Only less than 5\% of those vaccinated have headaches that last longer than 3 days. Focal neurological signs such as speech disorders, sensory disorders, or double vision occur in less than 3\%. The headaches are usually monophasic and do not show an undulating course. The headaches are mainly present in the forehead and temple area and show a dull, pressing character. In contrast, venous or arterial thrombosis can develop approximately 5-20 days after vaccination [23]. If headaches only commence at this point after the vaccination (or recur after the initial postvaccinal headache has subsided), accompanied by thrombocytopenia and focal neurological signs, this may indicate CVT.

Headaches attributed to a systemic viral infection require, according to ICHD-3 [25], diagnostic evidence of a systemic viral infection without evidence of meningitis or encephalitis. The headache must be closely related to the onset of the viral infection, aggravate as the viral infection worsens, and improve as the viral infection disappears. The pain is described as diffuse and of moderate or severe intensity. However, headaches attributed to vaccination against COVID-19 with the ChAdOx1 nCoV-19 (AZD1222) vaccine are not due to a systemic viral infection. For the first time, we describe the precise time between vaccination and onset of the headache, the headache duration, the headache character, the location, and the specific accompanying symptoms in this study. These characteristics have not yet found their way into the international headache classification.

The pathophysiological mechanisms of headache attributed to vaccination against COVID-19 remain unclear. Whether the S glycoprotein of SARS-CoV-2, synthesized intracellularly using the gene supplied by the vaccine, is itself responsible for the headache or whether it is due to the resulting immune response triggered by that protein $[8,26-32]$ must remain open at present. The intracellular formation of the spike protein and the triggered immune response could be directly related to the development of the headache phenotype described, including the accompanying symptoms of fatigue, chills, exhaustion, weakness, joint pain, and dizziness. It is speculated that microorganisms may activate anti-inflammatory substances such as nitric oxide, prostaglandins, and cytokines [29]. During a COVID-19 infection, vast amounts of proinflammatory cytokines can be released. According to our results, $36.1 \%$ of subjects with headaches attributed to vaccination reported chills and $30.4 \%$ fever as an accompanying symptom. Therefore, it can be assumed that inflammatory mediators are also involved in the development of headaches attributed to COVID-19 vaccination. Pre-existing primary headache disorders such as migraine lead to an increased duration and pain 
intensity of the headache attributed to COVID19 vaccination. It is possible that the sensitization with hyperexcitability of trigeminovascular neurons existing in primary headaches causes an increase in pain sensitivity and that this is relevant for the increased duration and pain intensity of headaches attributed to COVID-19 vaccination.

This study has a number of limitations. Participants with particularly pronounced headaches might have preferentially participated in this voluntary recruitment. The discovered clinical headache phenotype could thus represent particularly severe forms. However, we tried to capture the headache phenotype in the most detailed way possible by recruiting a very large number of participants. The vaccinations were not started until the age of 18 years. Therefore, it is unlikely that new-onset primary headaches are confounded with the data. Regarding the gender ratio with more women than men, a definitive statement is not possible. As study participation was voluntary and the population of vaccinees is unknown, it is possible that an excessive number of headache sufferers from the group of women participated in the study, given a disproportionate proportion of female vaccinees in the study. The responder rate of patients from residential care homes was significantly lower than the responder rate of university hospital staff. In addition, vaccination among hospital staff was initially very rapid. This explains the higher age distribution of the working participants. The high proportion of female participants can be explained by the high number of female employees in hospitals (female doctors, nurses, administrative staff, assistants). Because headaches occur very frequently irrespective of any vaccination, the data may be confounded by these other headaches. We did not attempt to delineate the frequency of headache occurrence after the COVID-19 vaccination. The phase 3 clinical trials of the various vaccination candidates provide this information by recording the frequency of possible side effects of the vaccination [5, 7-11, 16, 33-38]. Contrarily, no precise information regarding the clinical phenotype is contained in these studies. Whether the headache phenotype described here occurs in the same way or in a different form with other vaccines against COVID-19 remains still open and is subject to further subgroup analyses in this study series [39].

\section{CONCLUSIONS}

Headaches attributed to COVID-19 vaccination with the ChAdOx1 nCoV-19 (AZD1222) vaccine demonstrate an extensive and characteristic complex of symptoms. The set of accompanying symptoms, along with the temporal and spatial headache characteristics describe a unique headache phenotype for headaches attributed to COVID-19 vaccination. The findings have several important clinical implications for the differentiation of post-vaccinal headache and other primary as well as secondary headaches. On the basis of the findings, new diagnostic criteria for this form of headache can be developed.

\section{ACKNOWLEDGEMENTS}

We thank the participants of the study.

Funding. This research did not receive any specific grant from funding agencies in the public, commercial, or not-for-profit sectors. No funding was received for the publication of this article.

Authorship. All named authors meet the International Committee of Medical Journal Editors (ICMJE) criteria for authorship for this article, take responsibility for the integrity of the work as a whole, and have given their approval for this version to be published.

Authors' Contributions. Dr. Carl H. Göbeldesign and conceptualization of the study, interpretation of the results, contributed to statistical analysis, writing of the first draft of the manuscript. Dr. Axel Heinze-contribution to interpretation and analysis. Sarah Karstedtcontribution to interpretation and analysis. Mascha Morscheck-contribution to interpretation and analysis. Lilian Tashiro- 
contribution to interpretation and analysis. Dr. Anna Cirkel-contribution to interpretation and analysis. Prof. Qutyaba Hamid-contribution to interpretation and analysis. Prof. Rabih Halwani-contribution to interpretation and analysis. Dr. Mohamad-Hani Temsah-contribution to interpretation and analysis. Dr. Malte Ziemann-contribution to interpretation and analysis. Prof. Siegfried Görg-contribution to interpretation and analysis. Prof. Thomas Münte-design and conceptualization of the study, contribution to interpretation and analysis. Prof. Hartmut Göbel-design and conceptualization of the study, contributed to statistical analysis, co-writing of the manuscript.

Disclosures. Dr. Carl H. Göbel, Dr. Axel Heinze, Dr. Sarah Karstedt, Mascha Morscheck, Lilian Tashiro, Dr. Anna Cirkel, Prof. Qutyaba Hamid, Prof. Rabih Halwani, Dr. MohamadHani Temsah, Dr. Malte Ziemann, Prof. Siegfried Görg, Prof. Thomas Münte and Prof. Hartmut Göbel declare no financial conflicts and no competing interests.

Compliance with Ethics Guidelines. The ethics committee of the medical faculty of the Christian-Albrechts University Kiel approved the study (D403/21). All subjects gave their informed consent prior to participation. The study was performed in agreement with the Declaration of Helsinki.

Data Availability. The datasets generated during and/or analyzed during the current study are available from the corresponding author on reasonable request.

Open Access. This article is licensed under a Creative Commons Attribution-NonCommercial 4.0 International License, which permits any non-commercial use, sharing, adaptation, distribution and reproduction in any medium or format, as long as you give appropriate credit to the original author(s) and the source, provide a link to the Creative Commons licence, and indicate if changes were made. The images or other third party material in this article are included in the article's Creative Commons licence, unless indicated otherwise in a credit line to the material. If material is not included in the article's Creative Commons licence and your intended use is not permitted by statutory regulation or exceeds the permitted use, you will need to obtain permission directly from the copyright holder. To view a copy of this licence, visit http://creativecommons.org/licenses/by$\mathrm{nc} / 4.0 /$.

\section{REFERENCES}

1. Johns Hopkins University Coronavirus Resource Center. COVID-19 dashboard by the Center for Systems Science and Engineering (CSSE) at Johns Hopkins University. 2021. https://coronavirus.jhu. edu/map.html. Accessed 14 June 2021

2. Liu HQ, Yuan B, An YW, et al. Clinical characteristics and follow-up analysis of 324 discharged COVID-19 patients in Shenzhen during the recovery period. Int J Med Sci. 2021;18:347-55.

3. Dixon BE, Wools-Kaloustian K, Fadel WF, et al. Symptoms and symptom clusters associated with SARS-CoV-2 infection in community-based populations: results from a statewide epidemiological study. medRxiv. 2020. https://doi.org/10.1101/ 2020.10.11.20210922.

4. World Health Organization. COVID-19 vaccine tracker and landscape. 2021. https://www.who.int/ publications/m/item/draft-landscape-of-covid-19candidate-vaccines. Accessed 14 June 2021

5. Jackson LA, Anderson EJ, Rouphael NG, et al. An mRNA vaccine against SARS-CoV-2-preliminary report. N Engl J Med. 2020;383:1920-31.

6. Logunov DY, Dolzhikova IV, Shcheblyakov DV, et al. Safety and efficacy of an rAd26 and rAd5 vector-based heterologous prime-boost COVID-19 vaccine: an interim analysis of a randomised controlled phase 3 trial in Russia. Lancet. 2021;397: 671-81.

7. Logunov DY, Dolzhikova IV, Zubkova OV, et al. Safety and immunogenicity of an rAd26 and rAd5 vector-based heterologous prime-boost COVID-19 vaccine in two formulations: two open, non-randomised phase $1 / 2$ studies from Russia. Lancet. 2020;396:887-97.

8. Polack FP, Thomas SJ, Kitchin N, et al. Safety and efficacy of the BNT162b2 mRNA Covid-19 vaccine. N Engl J Med. 2020;383:2603-15. 
9. Ramasamy MN, Minassian AM, Ewer KJ, et al. Safety and immunogenicity of ChAdOx1 nCoV-19 vaccine administered in a prime-boost regimen in young and old adults (COV002): a single-blind, randomised, controlled, phase $2 / 3$ trial. Lancet. 2021;396:1979-93.

10. Tebas P, Yang S, Boyer JD, et al. Safety and immunogenicity of INO-4800 DNA vaccine against SARS-CoV-2: a preliminary report of an open-label, phase 1 clinical trial. EClinicalMedicine. 2021;31: 100689.

11. Xia S, Zhang Y, Wang Y, et al. Safety and immunogenicity of an inactivated SARS-CoV-2 vaccine, BBIBP-CorV: a randomised, double-blind, placebo-controlled, phase $1 / 2$ trial. Lancet Infect Dis. 2021;21:39-51.

12. Barrett JR, Belij-Rammerstorfer S, Dold C, et al. Phase $1 / 2$ trial of SARS-CoV-2 vaccine ChAdOx 1 nCoV-19 with a booster dose induces multifunctional antibody responses. Nat Med. 2021;27: 279-88.

13. Emary KRW, Golubchik T, Aley PK, et al. Efficacy of ChAdOx1 nCoV-19 (AZD1222) vaccine against SARS-CoV-2 variant of concern 202012/01 (B.1.1.7): an exploratory analysis of a randomised controlled trial. Lancet. 2021;397:1351-62.

14. European Medicines Agency. COVID-19 Vaccine AstraZeneca. 2021. Assessment report. Procedure No. EMEA/H/C/005675/0000. EMA/94907/2021: $1-181$

15. Ewer KJ, Barrett JR, Belij-Rammerstorfer S, et al. T cell and antibody responses induced by a single dose of ChAdOx1 nCoV-19 (AZD1222) vaccine in a phase 1/2 clinical trial. Nat Med. 2021;27:270-8.

16. Folegatti PM, Ewer KJ, Aley PK, et al. Safety and immunogenicity of the ChAdOx $1 \mathrm{nCoV}-19$ vaccine against SARS-CoV-2: a preliminary report of a phase $1 / 2$, single-blind, randomised controlled trial. Lancet. 2020;396:467-78.

17. Hodgson SH, Mansatta K, Mallett G, et al. What defines an efficacious COVID-19 vaccine? A review of the challenges assessing the clinical efficacy of vaccines against SARS-CoV-2. Lancet Infect Dis. 2021;21:e26-35.

18. Madhi SA, Baillie V, Cutland CL, et al. Efficacy of the ChAdOx1 nCoV-19 Covid-19 vaccine against the B.1.351 variant. N Engl J Med. 2021;384: 1885-98.

19. Voysey M, SaC C, Madhi SA, et al. Safety and efficacy of the ChAdOx1 nCoV-19 vaccine (AZD1222) against SARS-CoV-2: an interim analysis of four randomised controlled trials in Brazil, South Africa, and the UK. Lancet. 2021;397:99-111.

20. Voysey M, Costa Clemens SA, Madhi SA, et al. Single-dose administration and the influence of the timing of the booster dose on immunogenicity and efficacy of ChAdOx1 nCoV-19 (AZD1222) vaccine: a pooled analysis of four randomised trials. Lancet. 2021;397:881-91.

21. Wouters OJ, Shadlen KC, Salcher-Konrad M, et al. Challenges in ensuring global access to COVID-19 vaccines: production, affordability, allocation, and deployment. Lancet. 2021;397:1023-34.

22. Kim SH, Wi YM, Yun SY, et al. Adverse events in healthcare workers after the first dose of ChAdOx1 nCoV-19 or BNT162b2 mRNA COVID-19 vaccination: a single center experience. J Korean Med Sci. 2021;36:e107.

23. Greinacher A, Thiele $\mathrm{T}$, Warkentin $\mathrm{TE}$, et al. Thrombotic thrombocytopenia after ChAdOx1 nCov-19 vaccination. N Engl J Med. 2021;384: 2092-101.

24. Spadaro A, Scott KR, Koyfman A, et al. Cerebral venous thrombosis: diagnosis and management in the emergency department setting. Am J Emerg Med. 2021;47:24-9.

25. Headache Classification Committee of the International Headache Society (IHS). The International Classification of Headache Disorders, 3rd edition. Cephalalgia. 2018;38:1-211.

26. Alnefaie A, Albogami S. Current approaches used in treating COVID-19 from a molecular mechanisms and immune response perspective. Saudi Pharm J. 2020;28:1333-52.

27. Anwar MM. Immunotherapies and COVID-19 related neurological manifestations: a comprehensive review article. J Immunoassay Immunochem. 2020;41:960-75.

28. De Leon-Rodriguez SG, Hernandez-Rico B, OlmoVazquez GD, et al. SARS-CoV-2: previous coronaviruses, immune response, and development of vaccines. Bol Med Hosp Infant Mex. 2020;77: 252-61.

29. Magdy R, Hussein M, Ragaie C, et al. Characteristics of headache attributed to COVID-19 infection and predictors of its frequency and intensity: a cross sectional study. Cephalalgia. 2020;40:1422-31.

30. Orsucci D, Ienco EC, Nocita G, et al. Neurological features of COVID-19 and their treatment: a review. Drugs Context. 2020;9:5-1. https://doi.org/10. 7573/dic.2020-5-1. 
31. Schlickeiser S, Schwarz T, Steiner S, et al. Disease severity, fever, age, and sex correlate with SARSCoV-2 neutralizing antibody responses. Front Immunol. 2020;11:628971.

32. Steiner S, Sotzny F, Bauer S, et al. HCoV- and SARSCoV-2 cross-reactive T cells in CVID patients. Front Immunol. 2020;11:607918.

33. Ella R, Reddy S, Jogdand $\mathrm{H}$, et al. Safety and immunogenicity of an inactivated SARS-CoV-2 vaccine, BBV152: interim results from a doubleblind, randomised, multicentre, phase 2 trial, and 3-month follow-up of a double-blind, randomised phase 1 trial. Lancet Infect Dis. 2021;21:637-46.

34. Jones I, Roy P. Sputnik V COVID-19 vaccine candidate appears safe and effective. Lancet. 2021;397: 642-3.

35. Sadoff J, Le Gars M, Shukarev G, et al. Interim results of a phase 1-2a trial of Ad26.COV2.S Covid19 vaccine. N Engl J Med. 2021;384:1824-35.
36. Wu S, Zhong G, Zhang J, et al. A single dose of an adenovirus-vectored vaccine provides protection against SARS-CoV-2 challenge. Nat Commun. 2020;11:4081.

37. Zhu FC, Guan XH, Li YH, et al. Immunogenicity and safety of a recombinant adenovirus type-5-vectored COVID-19 vaccine in healthy adults aged 18 years or older: a randomised, double-blind, placebo-controlled, phase 2 trial. Lancet. 2020;396:479-88.

38. Zhu FC, Li YH, Guan XH, et al. Safety, tolerability, and immunogenicity of a recombinant adenovirus type-5 vectored COVID-19 vaccine: a dose-escalation, open-label, non-randomised, first-in-human trial. Lancet. 2020;395:1845-54.

39. Göbel C, Heinze A, Karstedt S, et al. Clinical characteristics of headache after vaccination against COVID-19 (coronavirus SARS-CoV-2) with the BNT162b2 mRNA vaccine: a multicentre observational cohort study. Brain Commun. 2021;3(192):1. https://doi.org/10.1093/braincomms/fcab169. 